\begin{tabular}{llllllll} 
O P E R A T I O N S R E S E A R C H A N D D E C I S I O N S \\
\hline No. 3
\end{tabular}

DOI: $10.37190 /$ ord 200302

\title{
GOVERNMENTAL COMBAT OF MIGRATION BETWEEN COMPETING TERRORIST ORGANISATIONS
}

\author{
KJELL HAUSKEN ${ }^{*}$ \\ Faculty of Science and Technology, University of Stavanger, 4036 Stavanger, Norway*
}

Each terrorist organisation is modelled with four coupled differential time equations for the evolution of ideologues, criminal mercenaries, captive participants, and capital sponsoring. Emigration of ideologues may cause unbounded growth of the organisation receiving ideologues. The organisation losing ideologues may reach a stationary state where ideologues are supported by capital sponsors and mercenaries. Emigration of mercenaries may cause the organisation losing mercenaries to experience growth. The organisation receiving mercenaries may lose capital sponsors permanently, allowing for the presence of mercenaries, or capital sponsors may rebound deterring mercenaries. Emigration of ideologues from one organisation to another requires more government intervention into the latter to ensure termination. Emigration of mercenaries from one organisation to another may require more government intervention into the latter, since mercenaries support ideologues. Competing terrorist organisations may facilitate their mutual extinction. Various intervention strategies are considered: the most threatening organisation is eliminated first, aided by competition from the least threatening, after which the remaining organisation is eliminated. The government's instantaneous and accumulated utilities are analysed through time and compared, depending on emigration, competition, and government intervention strategies.

Keywords: terrorism, terrorist organisations, ideologues, mercenaries, captive participants, sponsors, evolution, dynamics, simulation, migration, governments, intervention, differential equations

\section{Introduction}

\subsection{Background}

Terrorist organizations come in all shapes and forms. New organizations are formed. Old organizations die. Participants migrate back and forth among terrorist organizations. For example, migration towards the ISIS terror group was evident in 2014.

*Email address: kjell.hausken@uis.no

Received 31 January 2019, accepted 16 October 2020 
Some migration has occurred from Al-Qaeda. Competition ${ }^{1}$ may occur both if their objectives overlap and contradict each other. For example, various factions of the IRA compete with each other. The internal composition of each terrorist organization is essential, i.e., how it is composed of ideologues and captive participants, and whether it receives funding from sponsors, or from criminal mercenaries which may compromise the ideology.

Within this fluid and fluctuating environment through time governments need to assess how to operate. Challenging considerations are whether or not to intervene, how much and when to intervene, and towards which internal parts of which terrorist organizations to intervene. Relevant is also whether some terrorist organizations may compete with each other out of existence, or whether migration patterns may suggest, ignoring some terrorist organizations.

\subsection{Contribution}

Migration and competition between terrorist organisations are modelled through time with four coupled differential time equations. Each organisation has three labour stocks, i.e., ideologues, criminal mercenaries, and captive participants, and may receive capital sponsoring. Migration and competition are assumed possible for ideologues and mercenaries in different terrorist organisations. Captive participants support the ideologues or the mercenaries. Sponsors provide capital to terrorist organisations which are not too ideologically compromised with support from the criminal mercenaries.

Governments choose labour efforts as strategic choice variables to intervene in a targeted manner towards one or several terrorist organisations. The impact of intervention with different magnitudes and over different time horizons is illustrated. Intervention may be directed towards ideologues, mercenaries, captive participants, or capital sponsoring one or several terrorist organisations. Intervention is shown to alter the composition within and interaction between terrorist organisations through time. For various migration patterns of ideologues and mercenaries, and various degrees of competition, it is shown how various government intervention strategies impact whether terrorist organisations grow, are curtailed, or eliminated.

${ }^{1}$ This article interprets competition broadly to comprise fighting, war, struggle, conflict, battle, violence, etc., [25] interprets fighting as falling also into the category of interference struggles are political campaigns, rent-seeking manoeuvres for licenses and monopoly privileges [31], commercial efforts to raise rivals' costs [28] strikes and lockouts, and litigation - all being conflictual activities that need not involve actual violence. 


\subsection{Literature}

Chamberlain [6] assesses Al-Qaeda's recruitment, training, operations, and reaction to interventions. Saperstein [29] evaluates terrorism and counter terrorism mathematically, with policy implications. Bunn [4] studies terrorism and nuclear theft. Hausken and Zhuang [24] consider resource allocation between attack and defence for a government and a terrorist. Hausken [17] examines when to attack a terrorist. Bier and Hausken [3] endogenise negative and positive incentives towards terrorists. Extinction of organisations through warfare is considered by Hausken and Moxnes [23].

Caulkins et al. [5] evaluate how counter terrorism influences recruitment to terror organisations. They assess counter terrorism that provokes and does not provoke terrorism recruitment. They find two different steady states, one with the near elimination of the terrorist organisation, and one with many terrorists. Feichtinger and Novak [7] consider the terrorists' reaction when determining how to combat terrorism. They illustrate long-run persistent oscillations with nonunique transitory behaviour.

Excluding the time dimension, Hausken [14], Hausken and Gupta [20-22], and Hausken et al. [18] model ideologues and criminal mercenaries. Including the time dimension, Kaminskiy and Ayyub [27] present a model to argue that if a terrorist cell is not disabled after 2-3 half-lives, then a new terrorism intervention policy is needed. Feinstein and Kaplan [8] scrutinise short term and long term attacks for a terrorist organisation. Udwadia et al. [32] evaluate through time interventions against terrorists those susceptible to terrorist and pacifist propaganda, and pacifists. Ignoring migration between terrorist organisations [12, 13, 15, 16], models governments, ideologues, capital sponsors, mercenaries, and captive participants in terrorist organisations. Abbas et al. [1] show methodologies for decreasing terrorism risks and applying homeland security resources efficiently.

In related work, Berman and Gavious [2] study defence against terrorist attacks to minimise the disutility of terrorist attacks. Golany et al. [9] consider the defence of multiple sites against strategic and probabilistic uncertainty. Insua et al. [26] evaluate defence against threats from multiple sites. Further research on attack and defence of multiple sites has been conducted by Zhang and Zhuang [34], assuming multiple attack types, by Zhang et al. [35], accounting for risk preferences, by Shan and Zhuang [30], assuming multiple periods and cumulative defensive resource allocation, and by Guan et al. [10], assuming budget constraints. Hausken and Bier [19] and Xu and Zhuang [33] consider defence against several attackers.

Article organisation: Section 2 presents the model. Section 3 considers emigration. Section 4 considers emigration and competition. Section 5 evaluates government intervention, no competition, and emigration. Section 6 evaluates government intervention, competition, and emigration. Section 7 concludes the study. 


\section{The model}

\subsection{The evolution of $N$ terrorist organisations}

The model consists of four differential equations for the dynamics within each terrorist organisation, government intervention, competition or war between terrorist organisations, and migration between terrorist organisations, i.e.,

$$
\begin{aligned}
\dot{I}_{i}= & a_{i} K_{i}+e_{i} M_{i}+n_{i} C_{i}-\theta_{i} K_{i} M_{i}-b_{i} I_{i}-s_{i} \sum_{k=1}^{Q} G_{k l i}-\sum_{j=1, j \neq i}^{N} \alpha_{i j} x_{i j} I_{j} \\
& -\sum_{j=1}^{N} \max \left(\gamma_{i j t}, 0\right) \mu_{I j i t} I_{i}+\sum_{j=1}^{N} \max \left(\gamma_{j i t}, 0\right) \mu_{I j i t} I_{j} \\
\dot{K}_{i}= & c_{i} I_{i}-f_{i} M_{i}-d_{i} K_{i}-u_{i} \sum_{k=1}^{Q} G_{k K i} \\
\dot{M}_{i}= & g_{i} I_{i}+o_{i} C_{i}+h_{i} K_{i}-\varphi_{i} I_{i} K_{i}-m_{i} M_{i}-v_{i} \sum_{k=1}^{Q} G_{k M i}-\sum_{j=1, j \neq i}^{N} \beta_{i j} y_{i j} M_{j} \\
& -\sum_{j=1}^{N} \max \left(\lambda_{i j t}, 0\right) \mu_{M i j t} M_{i}+\sum_{j=1}^{N} \max \left(\lambda_{j i t}, 0\right) \mu_{M j i t} M_{j} \\
\dot{C}_{i}= & p_{i} I_{i}+q_{i} M_{i}-r_{i} C_{i}-w_{i} \sum_{k=1}^{Q} G_{k C i} \\
I_{i} \geq & 0, K_{i} \geq 0, M_{i} \geq 0, C_{i} \geq 0
\end{aligned}
$$

where a dot above a variable means time differentiation $d / d t, t$ is time, subscripts $i$ and $j$ express terrorist organisations $i$ and $j, i, j=1,2, \ldots, N, i \neq j$, and all parameters are assumed to be positive or zero.

In (1) ideologue labour $I_{i} \geq 0$ in terrorist organisation $i, i=1, \ldots, N$, increases with the increase of capital $K_{i} \geq 0$, mercenary labour $M_{i} \geq 0$, and captive participants labour $C_{i} \geq 0$, decreases with the product $K_{i} M_{i}$, constrained by its own growth. The variables $K_{i}$ and $M_{i}$ cannot impact $I_{i}$ without limits. Criminal mercenaries deter capital sponsors 
since they are perceived to dilute or water out the ideological purity of the terrorist organisation. Thus, Gupta [11], Hausken [14], Hausken et al. [18], Hausken and Gupta [20-22] show that terrorist organisations devaluing or debasing themselves to become criminal, such as, e.g., FARC, Abu Sayaaf, and various spinoffs of the Northern Irish IRA, are less successful recruiting ideologically committed sponsors. Hence, jointly high $K_{i}$ and $M_{i}$ is detrimental to ideologue labour $I_{i}$. Accordingly, we subtract $\theta_{i} K_{i} M_{i}$ from the right hand side of $\dot{I}_{i}$ in (1). For example, the term $\theta_{i} K_{i} M_{i}$ is large when both $K_{i}$ and $M_{i}$ are large, and small when either $K_{i}$ or $M_{i}$ is small.

Capital $K_{i}$ increases with ideologue labour $I_{i}$, decreases with mercenary labour $M_{i}$, constrained by its own growth. Mercenary labour $M_{i}$ increases with ideologue labour $I_{i}$, captive participants labour $C_{i}$, and capital $K_{i}$, decreases with the product $I_{i} K_{i}$, constrained by its own growth. Subtracting $\varphi_{i} I_{i} K_{i}$ on the right hand side of $\dot{M}_{i}$ in (1) is analogous to subtracting $\varphi_{i} I_{i} K_{i}$ on the right hand side of $\dot{I}_{i}$ in (1). The reasoning is that both $K_{i}$ and $I_{i}$ cannot impact $M_{i}$ positively without limits. For example, substantial capital sponsoring $K_{i}$ benefits ideologue labour $I_{i}$, which causes mercenary labour $M_{i}$ to decrease in practice, so that terrorist organisation $i$ becomes purer. Captive participants labour $C_{i}$ increases with ideologue labour $I_{i}$ and mercenary labour $M_{i}$, constrained by its own growth. The non-negative parameters $a, e, n, c, g, o, h, p, q$ are growth rates, and $\theta, b, f, d, \varphi, m, r$ are non-negative depreciation rates.

In (1), government $k, k=1,2, \ldots, Q \geq 1$ intervenes in terrorist organisation $i, i=1, \ldots$, $N \geq 1$ with labour efforts $G_{k l i}, G_{k K i}, G_{k M i}, G_{k C i}$ and non-negative unit effort costs $s_{i}, u_{i}, v_{i}$, $w_{i}$ against ideologue labour $I_{i}$, capital $K_{i}$, mercenary labour $M_{i}$, and captive participants labour $C_{i}$, respectively. Government $k$ 's labour efforts $G_{k i l}, G_{k K i}, G_{k M i}, G_{k C i}$ are positive if government $k$ suppresses terrorism, and negative when government $k$ sponsors terrorism. When government $k$ suppresses (sponsors) terrorism, terrorist organisation $i$ is impacted negatively (positively) by $s_{i} \sum_{k=1}^{Q} G_{k I i}, u_{i} \sum_{k=1}^{Q} G_{k K i}, v_{i} \sum_{k=1}^{Q} G_{k M i}, w_{i} \sum_{k=1}^{Q} G_{k C i}$, respectively, for $I_{i}, K_{i}, M_{i}$, and $C_{i}$.

In (1), terrorist organisation $i$ allocates a fraction $x_{i j}$ of ideologue labour $I_{i}$ to fight ideologue labour $I_{j}$ in organisation $j$, and a fraction $y_{i j}$ of mercenary labour $M_{i}$ to fight mercenary labour $M_{j}$ in organisation $j, 0 \leq x_{i j}, y_{i j} \leq 1, \sum_{j=1, j \neq i}^{N} x_{i j}=\sum_{j=1, j \neq i}^{N} y_{i j}=1$. Terrorist organisation $i$ is impacted negatively by $\sum_{j=1, j \neq i}^{N} \alpha_{i j} x_{i j} I_{j}$ for ideologue labour $I_{i}$, and negatively by $\sum_{j=1, j \neq i}^{N} \beta_{i j} y_{i j} M_{j}$ for mercenary labour $M_{i}$, where $\alpha_{i j} \geq 0$ and $\beta_{i j} \geq 0$ are loss 
rates. Hence, ideologue and mercenary labour in terrorist organisation $i$ suffer a loss rate proportional to the strengths of ideologue and mercenary labour in the competing terrorist organisation $j, j \neq i, i, j=1, \ldots, N$.

In (1), the negative term $\sum_{j=1}^{N} \max \left(\gamma_{i j t}, 0\right) \mu_{I i t} I_{i}$ expresses emigration of ideologue labour $I_{i}$ from organisation $i$ to organisation $j, j \neq i, i, j=1, \ldots, N$. First, $\gamma_{i j t}$ expresses how organisation $j$ is more attractive than organisation $i$ at time $t$ for ideologue labour $I_{i}$ when $\gamma_{j i t}$ $>0$, equally attractive when $\gamma_{i j t}=0$, and less attractive when $\gamma_{i j t}<0$, where $\gamma_{i j t}=-\gamma_{j i t}$. The attractiveness parameter is also a proportionality parameter which scales the extent to which ideologue labour $I_{i}$ moves from organisation $i$ to organisation $j$. The max function $\max \left(\gamma_{i j t}\right.$, 0 ) ensures that the term is only operational when $\gamma_{i j t}>0$, causing ideologue labour $I_{i}$ to move from organisation $i$ to organisation $j$. Hence, $-\infty<\gamma_{i j t}<\infty$ and $\gamma_{i i t}=0$. Second, $\mu_{i j t}$ expresses how organisation $i$ controls the outflow of ideologue labour $I_{i}$ from organisation $i$ to organisation $j$ at time $t$. Complete $100 \%$ control is expressed as $\mu_{i j t}=0$, causing no emigration of ideologue labour $I_{i}$ from organisation $i$ to organisation $j$ at time $t$. No control is expressed as $\mu_{i j t}=1$, causing emigration of ideologue labour $I_{i}$ from organisation $i$ to organisation $j$ at time $t$ as determined by $\sum_{j=1}^{N} \max \left(\gamma_{i j t}, 0\right) I_{i}$, where $0 \leq \mu_{I j i t} \leq 1$. Third, proportionality with ideologue labour $I_{i}$ in $\sum_{j=1}^{N} \max \left(\gamma_{i j t}, 0\right) \mu_{I j i t} I_{i}$ is assumed since more ideologue labour $I_{i}$ in organisation $i$ at time $t$ can be expected to cause more emigration when organisation $j$ is more attractive than organisation $i$. The mirror positive term $\sum_{j=1}^{N} \max \left(\gamma_{j i t}, 0\right) \mu_{I j i t} I_{j}$ in (1) applies when $\gamma_{i j t}<0$. Then organisation $i$ is more attractive than organisation $j$ at time $t$, and immigration to organisation $i$ from organisation $j$, proportional to ideologue labour $I_{i}$ in organisation $j$, and adjusted by organisation $j$ 's control parameter $\mu_{I j i t}, 0 \leq \mu_{I j i t} \leq 1$, can be expected.

In (1), the analogous negative term $\sum_{j=1}^{N} \max \left(\lambda_{i j t}, 0\right) \mu_{M i j t} M_{i}$ applies for emigration of mercenary labour $M_{i}$ from organisation $i$ to organisation $j, j \neq i, i, j=1, \ldots, N$. First, $\lambda_{i j t}$ expresses how organisation $j$ is more attractive than organisation $i$ at time $t$ for mercenary labour $M_{i}$ when $\lambda_{i j t}>0$, equally attractive when $\lambda_{i j t}=0$, and less attractive when $\lambda_{i j t}<0$, where $\lambda_{i j t}=-\lambda_{j i t},-\infty<\lambda_{i j t}<\infty$ and $\lambda_{i i t}=0$. Second, $\mu_{M i j t}$ expresses how organisation $i$ controls the outflow of mercenary labour $M_{i}$ from organisation $i$ to organisation $j$ at time $t, 0 \leq \mu_{M i j t} \leq 1$. Third, proportionality with mercenary labour $M_{i}$ is assumed, 
analogously to proportionality with ideologue labour $I_{i}$ in $\sum_{j=1}^{N} \max \left(\gamma_{i j t}, 0\right) \mu_{i j t} I_{i}$. The mirror positive term $\sum_{j=1}^{N} \max \left(\lambda_{j i t}, 0\right) \mu_{M j i t} M_{j}$ in (1) applies when $\lambda_{i j t}<0$, where $0 \leq \mu_{M j i t} \leq 1$.

\subsection{The $Q$ governments' utilities}

Government $k$ 's instantaneous utility $U_{k i}$ at time $\tau$ due to the presence of terrorist organisation $i, i=1, \ldots, N, k=1,2, \ldots, Q, 0 \leq \tau \leq t$, is

$$
\begin{aligned}
U_{k i}= & -\left(A_{k i} I_{i}^{z_{k i}}+B_{k i} K_{i}^{z_{k i}}+D_{k i} M_{i}^{z_{k i}}+E_{k i} C_{i}^{z_{k i}}\right)^{1 / z_{k i}} \\
& -F_{k i} G_{k I i}-H_{k i} G_{k K i}-J_{k i} G_{k M i}-L_{k i} G_{k C i}
\end{aligned}
$$

where $G_{k I i}, G_{k K i}, G_{k M i}, G_{k C i}$ are government k's labour intervention efforts with non-negative unit costs $F_{k i}, H_{k i}, J_{k i}, L_{k i}$, respectively, to decrease ideologue labour $I_{i}$, capital sponsoring $K_{i}$, mercenary labour $M_{i}$, and captive participants labour $C_{i}$ in terrorist organisation $i$. The non-negative weight parameters $A_{k i}, B_{k i}, D_{k i}, E_{k i}$ express how government $k$ weighs the relative disadvantage of the three labour stocks $I_{i}, M_{i}, C_{i}$, and capital sponsoring $K_{i}$. The elasticity of substitution for government $k$ as impacted by terrorist organisation $i$ is $1 /\left(1-z_{k i}\right)$, where $z_{k i}=1$ means perfect substitutes, $-\infty<z_{k i} \leq 1$. When $z_{k i}$ approaches minus infinity, perfect complements occur. When $z_{k i}$ approaches zero, the Cobb-Douglas utility function arises.

Government $k$ 's utility $U_{k}$ across the $N$ terrorist organisations is additive, i.e.,

$$
U_{k}=\sum_{i=1}^{N} U_{k i}
$$

where $U_{k i}$ is determined by (2). Government $k$ 's accumulated utilities $U_{k a i}$ and $U_{k a}$ from time $\tau=0$ to time $\tau=\mathrm{t}$, due to terrorist organisation $i$ and all $Q$ terrorist organisations, respectively, with time discount parameter $\delta_{k}, 0 \leq \delta_{k} \leq 1$, are

$$
U_{k a i}=\int_{\tau=0}^{\tau=t} \delta_{k}^{\tau} U_{k i} d \tau, \quad U_{k a}=\int_{\tau=0}^{\tau=t} \delta_{k}^{\tau} U_{k} d \tau
$$


Table 1 presents an overview of the content in the remainder of the article which focuses on emigration (Section 3), emigration and competition (Section 4), emigration and government intervention and no competition (Section 5), and emigration and competition and government intervention (Section 6).

Table 1. Article overview

\begin{tabular}{|c|c|c|c|c|c|c|c|c|}
\hline Section & Figure & Panels & $\gamma_{j i t}$ & $\lambda_{j i t}$ & $\alpha_{i j}=\alpha_{j i}$ & $G_{k I i}$ & $G_{k l j}$ & Characteristic \\
\hline \multirow{5}{*}{3} & \multirow{5}{*}{1} & $\mathrm{a} 1, \mathrm{a} 2$ & 0 & 0 & 0 & 0 & 0 & benchmark \\
\hline & & $\mathrm{b} 1, \mathrm{~b} 2$ & 0.125 & 0 & 0 & 0 & 0 & \multirow{4}{*}{ only emigration } \\
\hline & & $\mathrm{c} 1, \mathrm{c} 2$ & 0 & 1 & 0 & 0 & 0 & \\
\hline & & $\mathrm{d} 1, \mathrm{~d} 2$ & 0.125 & 1 & 0 & 0 & 0 & \\
\hline & & e1, e2 & 0.5 & 1 & 0 & 0 & 0 & \\
\hline \multirow{3}{*}{4} & \multirow{3}{*}{2} & $\mathrm{a} 1, \mathrm{a} 2$ & 0 & 0 & 0.1 & 0 & 0 & competition \\
\hline & & b1, b2 & 0.125 & 0 & 0.1 & 0 & 0 & \multirow{2}{*}{$\begin{array}{l}\text { emigration } \\
\text { and competition }\end{array}$} \\
\hline & & $\mathrm{c} 1, \mathrm{c} 2$ & 0 & 1 & 0.1 & 0 & 0 & \\
\hline \multirow{4}{*}{5} & \multirow{4}{*}{3} & $\mathrm{a} 1, \mathrm{a} 2$ & 0 & 0 & 0 & 0.41 & 0.41 & $\begin{array}{l}\text { only government } \\
\text { intervention }\end{array}$ \\
\hline & & $\mathrm{b} 1, \mathrm{~b} 2$ & 0.125 & 0 & 0 & 0.41 & 0.24 & \multirow{3}{*}{$\begin{array}{l}\text { emigration } \\
\text { and government } \\
\text { intervention } \\
\end{array}$} \\
\hline & & $\mathrm{c} 1, \mathrm{c} 2$ & 0 & 1 & 0 & 0.9 & 0.26 & \\
\hline & & $\mathrm{d} 1, \mathrm{~d} 2$ & 0.125 & 1 & 0 & 0.9 & 0.26 & \\
\hline \multirow{3}{*}{6} & \multirow{3}{*}{4} & $\mathrm{a} 1, \mathrm{a} 2$ & 0 & 0 & 0.1 & 0.27 & 0.27 & $\begin{array}{l}\text { competition, } \\
\text { government intervention }\end{array}$ \\
\hline & & $\mathrm{b} 1, \mathrm{~b} 2$ & 0.125 & 0 & 0.1 & $0.68 ; 0$ & $0 ; 0.5$ & \multirow{2}{*}{$\begin{array}{l}\text { emigration, } \\
\text { competition, } \\
\text { government intervention }\end{array}$} \\
\hline & & $\mathrm{c} 1, \mathrm{c} 2$ & 0 & 1 & 0.1 & $0.69 ; 0$ & $0 ; 3$ & \\
\hline
\end{tabular}

Emigration (Section 3), emigration and competition (Section 4), emigration and government intervention and no competition (Section 5), and emigration and competition and government intervention (Section 6). $\gamma_{j i t}$ - ideologue emigration from organisation $j$ to organisation $i, \lambda_{j i t}$ - mercenary emigration from organisation $j$ to organisation $i, \alpha_{i j}=\alpha_{j i}$ - ideologue competition between organisation $i$ and organisation $j$, $G_{k l i}$ - government intervention into organisation $i, G_{k l j}$ - government intervention into organisation $j$.

\section{Analysing emigration for two terrorist organisations}

\subsection{The evolution of $N=2$ terrorist organisations}

Figure 1 exemplifies (1) for $N=2$ organisations $i$ and $j$, i.e., $x_{i j}=x_{j i}=y_{i j}=y_{j i}=1$, no competition $\alpha_{i j}=\alpha_{j i}=\beta_{i j}=\beta_{j i}=0$ between the two organisations, and no government intervention, i.e., $G_{k I i}=G_{k K i}=G_{k M i}=G_{k C i}=0, k=1,2, \ldots, Q, i, j=1,2, i \neq j$. The initial values for the variables are $I_{i}(0)=I_{j}(0)=2, K_{i}(0)=K_{j}(0)=M_{i}(0)=M_{j}(0)=C_{i}(0)=C_{j}(0)$ $=0$, to express that ideologues are crucial in starting terrorist organisations.

The benchmark parameter values are chosen to be plausible and simple, while capturing different representative characteristics of the model. Thus many parameter values 
are set equal to one. For example, we choose $a_{i}=1$ which in (1) means that capital $K_{i}$ on the right hand side impacts the derivative of ideologue labour $\dot{I}_{i}$ on the left hand side with a proportionality parameter equal to one, which is assessed to be plausible and simple as a benchmark. Similarly, we set government $k$ 's unit effort costs, such as $s_{i}=1$ to combat ideologue labour $I_{i}$, equal to one, and adjust government $k$ 's labour effort $G_{k l i}$ at time $t$ to combat ideologue labour $I_{i}$ in terrorist organisation $k$ to ensure suitable impact as illustrated in the simulations. Connecting the parameter values to the real world scenarios mentioned in Section 1 (ISIS, Al-Qaeda, etc.) is left for future empirical research. We hypothesise the ratios of the benchmark parameter values chosen in this article may reflect the ratios of the benchmark parameter values determined by empirical research.

The benchmark parameter values are $a_{i}=a_{j}=c_{i}=c_{j}=d_{i}=d_{j}=e_{i}=e_{j}=f_{i}=f_{j}=h_{i}=h_{j}$ $=m_{i}=m_{j}=r_{i}=r_{j}=s_{i}=s_{j}=u_{i}=u_{j}=v_{i}=v_{j}=w_{i}=w_{j}=\mu_{\text {Iijt }}=\mu_{\text {jijt }}=\mu_{\text {Mijt }}=\mu_{M j i t}=1, b_{i}=b_{j}=g_{i}$ $=g_{j}=0.8, \theta_{i}=\theta_{j}=0.3, \varphi_{i}=\varphi_{j}=0.6, n_{i}=n_{j}=o_{i}=o_{j}=p_{i}=p_{j}=q_{i}=q_{j}=0.25$. Growth of $I_{i}$ and $I_{j}$ is obtained by $b_{i}=b_{j}=0.8$. That is, ideologue labours $I_{i}$ and $I_{j}$ in (1) depreciate $20 \%$ less by themselves than $M_{i}, M_{j}, C_{i}, C_{j}, K_{i}, K_{j}$. Choosing $g_{i}=g_{j}=0.8$ expresses that mercenary labours $M_{i}$ and $M_{j}$ in (1) are $20 \%$ less positively impacted by $I_{i}$ and $I_{j}$ than capital sponsoring $K_{i}$ and $K_{j}$ of the two organisations is impacted by $I_{i}$ and $I_{j}$. We assume that organisation $i$ does not control the outflow of ideologue labour $I_{i}$ and mercenary labour $M_{i}$, i.e., $\mu_{\text {Iijt }}=\mu_{i j i t}$ $=\mu_{M i j t}=\mu_{M j i t}=1$. Figure 1 panel a1 assumes the benchmark no emigration $\gamma_{i j t}=\gamma_{j i t}=\lambda_{i j t}=\lambda_{j i t}$ $=0$. The ideologue labours $I_{i}$ and $I_{j}$, capital sponsoring $K_{i}$ and $K_{j}$, and captive participants labours $C_{i}$ and $C_{j}$ increase without bounds, i.e., $\lim _{t \rightarrow \infty} I_{i}=\lim _{t \rightarrow \infty} I_{j}=\lim _{t \rightarrow \infty} K_{i}=\lim _{t \rightarrow \infty} K_{j}$ $=\lim _{t \rightarrow \infty} C_{i}=\lim _{t \rightarrow \infty} C_{j}=\infty$. This increase is incompatible with mercenary labours $M_{i}$ and $M_{j}$ due to $-\varphi_{i} I_{i} K_{i}$ and $-\varphi_{j} I_{j} K_{j}$ in (1), which expresses that mercenary labours $M_{i}$ and $M_{j}$ become superfluous and detrimental when ideologue labours $I_{i}$ and $I_{j}$, can rely on capital sponsoring $K_{i}$ and $K_{j}$. Hence, the mercenary labours $M_{i}$ and $M_{j}$ in panel la first increase to a maximum, and thereafter decrease to $M_{i}=M_{j}=0$ when $t>14.50$.

Figure 1 panel b1 assumes attractiveness $\gamma_{j i t}=0.125$ of organisation $i$ relative to organisation $j$ for ideologue labour $I_{j}$ at time $t$. That causes ideologue labour $I_{i}$ in organisation $i$ to increase more than in panel a1, $\lim _{t \rightarrow \infty} I_{i}=\infty$, and consequently $\lim _{t \rightarrow \infty} K_{i}$ $=\lim _{t \rightarrow \infty} C_{i}=\infty$, and causes ideologue labour $I_{j}$ in organisation $j$ to be lower than in panel a1, $\lim _{t \rightarrow \infty} I_{j}=2.82$. Limit values are determined numerically. The higher $I_{i}$ is detrimental to mercenary labour $M_{i}$ in organisation $i$ which decreases to $M_{i}=0$ quicker than in panel a1, i.e., when $t>8.92$. The lower $I_{j}$ in organisation $j$ deters sponsors, and thus capital sponsoring $K_{j}$ is lower than in panel a1, $\lim _{t \rightarrow \infty} K_{j}=0.87$. The lower $I_{j}$ and $K_{j}$ in organisation $j$ allow for the presence of mercenary labour $M_{j}$ in organisation $j$ which does not vanish, but 
approaches a constant value, $\lim _{t \rightarrow \infty} M_{j}=1.95$, and consequently $\lim _{t \rightarrow \infty} C_{j}=1.19$. Continuously losing some ideologue labour $I_{j}$ prevents organisation $j$ from growing unboundedly. It also does not go extinct. The remaining ideologue labour $I_{j}$ gets moderately sustained by capital sponsoring $K_{j}$ which tolerates some presence of mercenary labour $M_{j}$.

Figure 1 panel $\mathrm{c} 1$ assumes attractiveness $\lambda_{j i t}=1$ of organisation $i$ relative to organisation $j$ for mercenary labour $M_{j}$ at time $t$. That causes mercenary labour $M_{j}$ in organisation $j$ to experience a lower and shorter inverse $\mathrm{U}$ shape, decreasing to $M_{j}=0$ quicker than in panel a1, i.e., when $t>11.79$, after which emigration from organisation $j$ ceases. It also causes mercenary labour $M_{i}$ in organisation $i$ initially to increase more than in panel a1, which gives a temporary boost to ideologue labour $I_{i}$ in organisation $i$, $\lim _{t \rightarrow \infty} I_{i}=\infty$. The temporarily high $M_{i}$ is detrimental to capital sponsoring $K_{i}$ which experiences a temporary dip. Since $I_{i}$ sustains a high level relative to $M_{i}$, capital sponsoring $K_{i}$ gradually returns, $\lim _{t \rightarrow \infty} K_{i}=\lim _{t \rightarrow \infty} C_{i}=\infty$, which deters mercenary labour $M_{i}$ which decreases to $M_{i}=0$ when $t>11.99$. That organisation $j$ loses some mercenary labour is beneficial for capital sponsoring $K_{j}$, and thus also for ideologue labour $I_{j}$, and in this case for captive participants labour $C_{j}$, which increases quicker than in panel a1, $\lim _{t \rightarrow \infty} K_{j}$ $=\lim _{t \rightarrow \infty} I_{j}=\lim _{t \rightarrow \infty} C_{j}=\infty$.

Figure 1 panel d 1 combines the effects in panels $\mathrm{b} 1$ and $\mathrm{c} 1$, i.e., both attractiveness $\gamma_{j i t}=0.125$ for ideologue labour $I_{j}$ and attractiveness $\lambda_{j i t}=1$ for mercenary labour $M_{j}$, of organisation $i$ relative to organisation $j$ at time $t$. That causes an inverse $\mathrm{U}$ shaped curve for mercenary labour $M_{i}$, reaching $M_{i}=0$ when $t>10.77$. The evolution of organisation $i$ is similar to that of panels b1 and $\mathrm{c} 1, \lim _{t \rightarrow \infty} I_{i}=\lim _{t \rightarrow \infty} K_{i}=\lim _{t \rightarrow \infty} C_{i}=\infty$. Mercenary labour $M_{j}$ is lower than in panel b1, since organisation $j$ loses mercenaries through $\lambda_{j i t}=1$. Mercenary labour $M_{j}$ remains higher for a longer period of time than in panel $\mathrm{c} 1$, since

Fig. 1. Ideologue labours $I_{i}$ and $I_{j}$, capital $K_{i}$ and $K_{j}$, mercenary labours $M_{i}$ and $M_{j}$, and captive participants labours $C_{i}$ and $C_{j}$, in $N=2$ organisations $i$ and $j, i, j=1,2, i \neq j$, and government $k$ 's instantaneous utility $U_{k}$ and accumulated utility $U_{k a}, k=1, \ldots, Q$ as functions of time $t$ with benchmark parameter values $a_{i}=a_{j}=c_{i}=c_{j}=d_{i}=d_{j}=e_{i}=e_{j}=f_{i}=f_{j}=h_{i}=h_{j}=m_{i}=m_{j}=r_{i}=r_{j}=s_{i}=s_{j}=u_{i}=u_{j}=v_{i}=v_{j}=w_{i}=w_{j}=\mu_{\text {Iijt }}$ $=\mu_{\text {Ijit }}=\mu_{M i j t}=\mu_{M j i t}=1, b_{i}=b_{j}=g_{i}=g_{j}=0.8, \theta_{i}=\theta_{j}=0.3, \varphi_{i}=\varphi_{j}=0.6, n_{i}=n_{j}=o_{i}=o_{j}=p_{i}=p_{j}=q_{i}=q_{j}$ $=0.25, \alpha_{i j}=\alpha_{j i}=\beta_{i j}=\beta_{j i}=\gamma_{i j}=\gamma_{j i}=\lambda_{i j}=\lambda_{j i}=0, I_{i}(0)=I_{j}(0)=2, K_{i}(0)=K_{j}(0)=M_{i}(0)=M_{j}(0)=C_{i}(0)$ $=C_{j}(0)=0, A_{k i}=A_{k j}=B_{k i}=B_{k j}=D_{k i}=D_{k j}=E_{k i}=E_{k j}=\delta_{k}=1, z_{k i}=z_{k j}=0.5, G_{k l i}=G_{k l j}=G_{k K i}=G_{k K j}=G_{k M i}=G_{k M j}$ $=G_{k C i}=G_{k C j}=0$. Division of $U_{k a}$ with 10 is for scaling purposes. Panels a1 and a2: benchmark, panels b1 and b2: $\gamma_{j i t}=0.125$, panels c1 and c2: $\lambda_{j i t}=1$, panels d1 and d2: $\gamma_{j i t}=0.125, \lambda_{j i t}=1$, panels e1 and e2: $\gamma_{j i t}=0.5, \lambda_{j i t}=1$ 

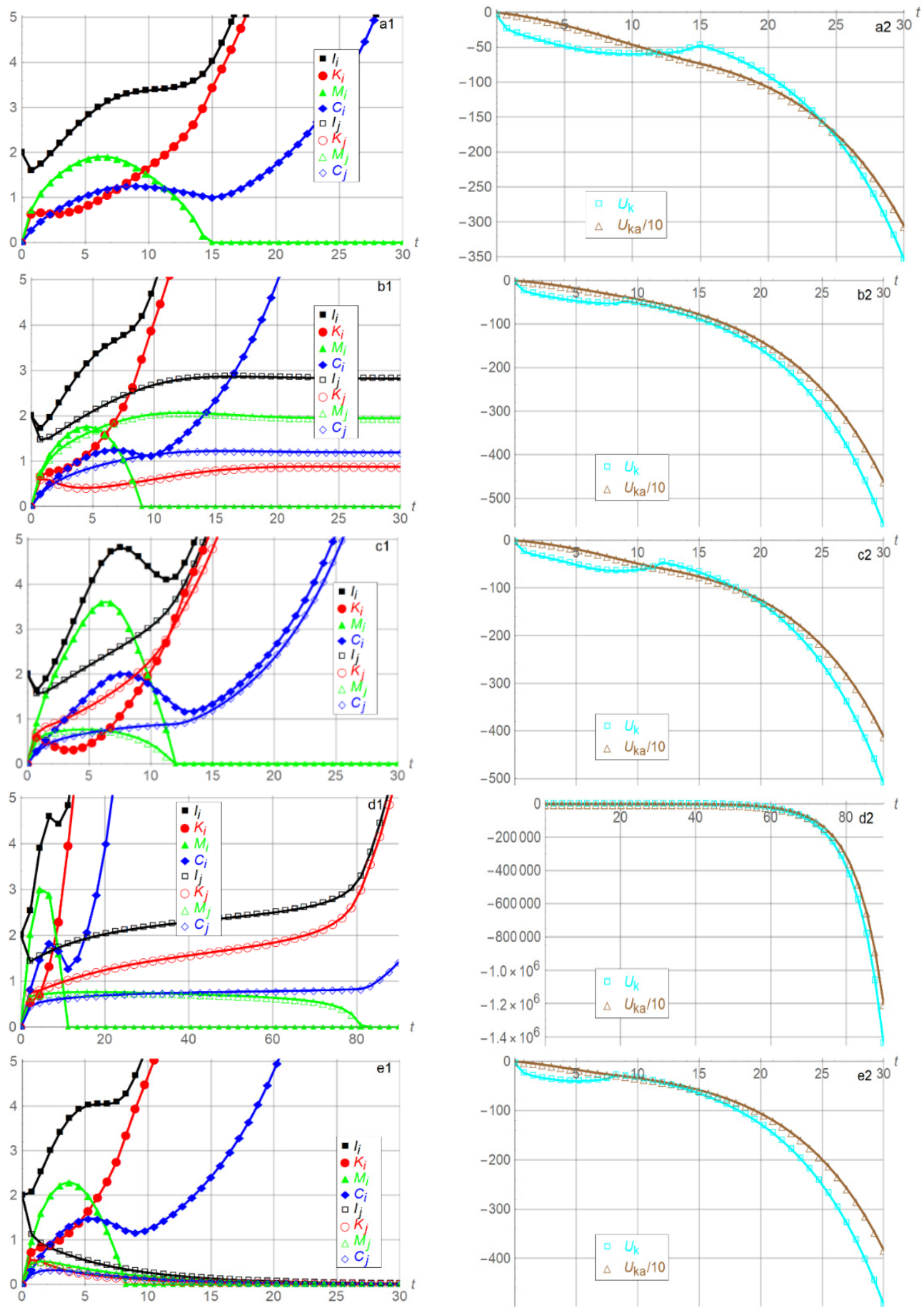
organisation $j$ loses ideologue labour $I_{j}$ due to $\gamma_{j i t}=0.125$, which partly deters capital sponsoring $K_{j}$, allowing some presence of mercenary labour $M_{j}$. Eventually, the low presence of mercenary labour $M_{j}$ gets deterred altogether by $I_{j}$ and $K_{j}$, reaching $M_{j}=0$ when $t>81.23$. That enables ideologue labour $I_{j}$, capital sponsoring $K_{j}$, and captive participants labour $C_{j}$ in organisation $j$ eventually to increase towards infinity, $\lim _{t \rightarrow \infty} I_{j}$ $=\lim _{t \rightarrow \infty} K_{j}=\lim _{t \rightarrow \infty} C_{j}=\infty$, although slower than for organisation $i$ due to the drainage of ideologue labour $I_{j}$ from organisation $j$ to organisation $i$.

None of the panels b1, c1, d1 cause organisation $j$ to go extinct. Higher attractiveness $\gamma_{j i t}=0.25$ for ideologue labour $I_{j}$ and equal attractiveness $\lambda_{j i t}=1$ (compared with panel d) for mercenary labour $M_{j}$ also does not cause extinction, although it causes lower levels of labours and capital sponsoring, i.e., $\lim _{t \rightarrow \infty} I_{j}=0.66, \lim _{t \rightarrow \infty} K_{j}=0.28, \lim _{t \rightarrow \infty} M_{j}=0.38$, and $\lim _{t \rightarrow \infty} C_{j}=0.26$, compared with panel b. However, even higher attractiveness $\gamma_{j i t}=0.5$ for ideologue labour $I_{j}$ and equal attractiveness $\lambda_{j i t}=1$ (compared with panel d) for mercenary labour $M_{j}$ terminates organisation $j$, as shown in Fig. 1 panel e1. Mercenary labour $M_{i}$ is inverse $\mathrm{U}$ shaped and reaches $M_{i}=0$ when $t>8.19$. Thereafter, organisation $i$ grows towards infinity without mercenary labour $M_{i}=0, \lim _{t \rightarrow \infty} I_{i}=\lim _{t \rightarrow \infty} K_{i}=\lim _{t \rightarrow \infty} C_{i}=\infty$, while organisation $j$ goes extinct, $\lim _{t \rightarrow \infty} I_{j}=\lim _{t \rightarrow \infty} K_{j}=\lim _{t \rightarrow \infty} M_{j}=\lim _{t \rightarrow \infty} C_{j}=0$. Extinction in panel e differs from panels b1, c1, and d1. The reason is that substantial emigration of ideologues and some emigration of mercenaries, as in panel e, is more detrimental for organisation $j$ than a more modest emigration. In contrast, modest emigration of only ideologues may enable organisation $j$ to sustain itself through mercenaries, as in panel b1 and when $\gamma_{j i t}=0.25$, as shown above.

\subsection{The $Q$ governments' utilities}

Figure 1 panels a2, b2, c2, d2, e2 exemplify (2), (3), (4) for the $N=2$ terrorist organisations in Section 3.1, i.e., no competition $\alpha_{i j}=\alpha_{j i}=\beta_{i j}=\beta_{j i}=0$ between the two organisations, for $Q$ equivalent governments not intervening, i.e., $G_{k l i}=G_{k K i}=G_{k M i}=G_{k C i}=0$, $k=1,2, \ldots, Q, i=1,2$. Government $k$ 's benchmark parameter values are $A_{k i}=B_{k i}=D_{k i}$ $=E_{k i}=\delta_{k}=1, z_{k i}=0.5$.

In Figure 1 panel a2, the instantaneous utility $U_{k}$ for government $k, k=1, \ldots, Q$, is affected by the inverse $\mathrm{U}$ shaped $M_{i}$ and $M_{j}$, and is initially $\mathrm{U}$ shaped. After the extinction of mercenary labours $M_{i}$ and $M_{j}$ when $t>14.50$, government $k$ benefits temporarily. Thereafter, $I_{i}, I_{j}, K_{i}, K_{j}, C_{i}, C_{j}$ approach infinity causing government $k$ 's instantaneous 
utility $U_{k}$ and accumulated utility $U_{k a} / 10$ to decrease towards minus infinity, i.e., $\lim _{t \rightarrow \infty} U_{k}=\lim _{t \rightarrow \infty} U_{k a}=-\infty$. Division of $U_{k a}$ with 10 is for scaling purposes.

In Figure 1 panel b2, attractiveness $\gamma_{j i t}=0.125$ of organisation $i$ relative to organisation $j$ for ideologue labour $I_{j}$ at time $t$, causes organisation $i$ to grow more substantially. Although organisation $j$ gets confined within bounds, both government $k$ 's utilities approach $\lim _{t \rightarrow \infty} U_{k}=\lim _{t \rightarrow \infty} U_{k a}=-\infty$ quicker than in panel a2 with no emigration.

In Figure 1 panel $\mathrm{c} 2$, attractiveness $\lambda_{j i t}=1$ of organisation $i$ relative to organisation $j$ for mercenary labour $M_{j}$ at time $t$ causes both organisations $i$ and $j$ to grow unboundedly, causing $\lim _{t \rightarrow \infty} U_{k}=\lim _{t \rightarrow \infty} U_{k a}=-\infty$. The evolution until time $t=30$ is similar (slightly more beneficial for government $k$ ) to that of panel $b$.

In Figure 1 panel d2, attractiveness $\gamma_{j i t}=0.125$ for ideologue labour $I_{j}$ and attractiveness $\lambda_{j i t}=1$ for mercenary labour $M_{j}$ of organisation $i$ relative to organisation $j$ at time $t$ causes both organisations $i$ and $j$ to grow unboundedly, causing $\lim _{t \rightarrow \infty} U_{k}=\lim _{t \rightarrow \infty} U_{k a}=-\infty$. At time $t=30, U_{k}=-434.58$ and $U_{k a} / 10=-412.96$, which is similar to panels a, b, and c.

In Figure 1 panel e2, four times higher attractiveness $\gamma_{j i t}=0.5$ for ideologue labour $I_{j}$ and attractiveness $\lambda_{j i t}=1$ for mercenary labour $M_{j}$, of organisation $i$ relative to organisation $j$ at time $t$, causes organisation $i$ to grow quickly and unboundedly, while organisation $j$ goes extinct, $\lim _{t \rightarrow \infty} U_{k}=\lim _{t \rightarrow \infty} U_{k a}=-\infty$. At time $t=30, U_{k}=-492.70$ and $U_{k a} / 10$ $=-382.82$. Government $k$ prefers the latter, compared with panels $\mathrm{b}, \mathrm{c}$, and $\mathrm{d}$.

\section{Analysing emigration and ideologue competition for two terrorist organisations}

This section assumes competition $\alpha_{i j}=\alpha_{j i}=0.1$ between ideologue labours $I_{i}$ and $I_{j}$ in organisations $i$ and $j$. For Fig. 2 panels a1 and a 2 assume the other assumptions are as in Fig. 1 panels a1 and a2, i.e., $\gamma_{i j}=\gamma_{j i}=\lambda_{i j}=\lambda_{j i}=\beta_{i j}=\beta_{j i}=0, G_{k I i}=G_{k K i}=G_{k M i}=G_{k C i}=0$, $k=1,2, \ldots, Q, i, j=1,2, i \neq j, I_{i}(0)=I_{j}(0)=2, K_{i}(0)=K_{j}(0)=M_{i}(0)=M_{j}(0)=C_{i}(0)=C_{j}(0)$ $=0, a_{i}=a_{j}=c_{i}=c_{j}=d_{i}=d_{j}=e_{i}=e_{j}=f_{i}=f_{j}=h_{i}=h_{j}=m_{i}=m_{j}=r_{i}=r_{j}=s_{i}=s_{j}=u_{i}=u_{j}=v_{i}$ $=v_{j}=w_{i}=w_{j}=\mu_{I j i t}=\mu_{\text {Ijit }}=\mu_{M i j t}=\mu_{M j i t}=1, b_{i}=b_{j}=g_{i}=g_{j}=0.8, \theta_{i}=\theta_{j}=0.3, \varphi_{i}=\varphi_{j}=0.6$, $n_{i}=n_{j}=o_{i}=o_{j}=p_{i}=p_{j}=q_{i}=q_{j}=0.25$. The competition without emigration prevents the ideologue labours $I_{i}$ and $I_{j}$ from growing unboundedly, instead approaching the constant $\lim _{t \rightarrow \infty} I_{i}=\lim _{t \rightarrow \infty} I_{j}=2.89$, constrained by $-\theta_{i} K_{i} M_{i}$ and $-\theta_{j} K_{j} M_{j}$ in (1). Capital sponsoring approaches $\lim _{t \rightarrow \infty} K_{i}=\lim _{t \rightarrow \infty} K_{j}=1.07$. The mercenary labours $M_{i}$ and $M_{j}$ approach the con- 
stant $\lim _{t \rightarrow \infty} M_{i}=\lim _{t \rightarrow \infty} M_{j}=1.82$, constrained by $-\varphi_{i} I_{i} K_{i}$ and $-\varphi_{j} I_{j} K_{j}$ in (1). Captive participants labours $C_{i}$ and $C_{j}$ approach $\lim _{t \rightarrow \infty} C_{i}=\lim _{t \rightarrow \infty} C_{j}=1$.18. Government $k$ 's instantaneous utility $U_{k}$ benefits from the competition, approaching the constant $\lim _{t \rightarrow \infty} U_{k}=-53.44$. Government $k$ 's accumulated utility $U_{k a} / 10$ approaches $\lim _{t \rightarrow \infty} U_{k a}=-\infty$ slower than in Fig. 1 panel a2.

Figure 2 panels b1 and b2 introduce ideologue competition $\alpha_{i j}=\alpha_{j i}=0.1$ to the assumptions in Fig. 1 panels b1 and b2, where ideologue labour $I_{j}$ in organisation $j$ moves to organisation $i$. That is detrimental to organisation $j$, which no longer sustains itself within bounds, but approaches extinction. The competition decreases ideologue labour $I_{j}$ in organisation $j$, which deters capital sponsoring which decreases to $K_{j}=0$ when $t>10.37$. Increased ideologue labour $I_{i}$ in organisation $i$ eventually decreases the need for mercenary labour $M_{i}$ which, after an inverse $\mathrm{U}$ shape, decreases to $M_{i}=0$ when $t>13.38$. Thereafter, ideologue labour $I_{j}$ in organisation $i$ decreases to $I_{j}=0$ when $t>16.66$, after which emigration ceases and $\lim _{t \rightarrow \infty} M_{j}=\lim _{t \rightarrow \infty} C_{j}=0$. Organisation $i$ is initially hampered by the competition, growing slightly slower than in Fig. 1 panel b1, but eventually unbounded growth occurs, $\lim _{t \rightarrow \infty} I_{i}=\lim _{t \rightarrow \infty} K_{i}=\lim _{t \rightarrow \infty} C_{i}=\infty$. Government $k$ again benefits from the competition, earning higher utilities than in Fig. 1 panel b2, though $\lim _{t \rightarrow \infty} U_{k}=\lim _{t \rightarrow \infty} U_{k a}=-\infty$.

Figure 2 panels $\mathrm{c} 1$ and $\mathrm{c} 2$ introduce ideologue competition $\alpha_{i j}=\alpha_{j i}=0.1$ to the assumptions in Fig. 1 panels $\mathrm{c} 1$ and $\mathrm{c} 2$, where mercenary labour $M_{j}$ in organisation $j$ moves to organisation $i$. That is also detrimental to organisation $j$, especially to mercenary labour $M_{j}$ which after a low and short inverse U shape approaches $\lim _{t \rightarrow \infty} M_{j}=0$ asymptotically. With limited support of mercenary labour $M_{j}$, ideologue labour $I_{j}$ in organisation $j$ suffers in the competition with organisation $i$ and follows and inverse $\mathrm{U}$ shaped form, reaching $I_{j}=0$ when $t>13.78$. Thus, capital sponsoring also dries up, $K_{j}=0$ when $t>13.91$, and $\lim _{t \rightarrow \infty} C_{j}=0$, as organisation $j$ approaches extinction. That contrasts with Fig. 1 panel $\mathrm{c} 1$ without ideologue competition, where ideologue labour $I_{j}$ increases unboundedly. In contrast, organisation $i$ experiences a temporary boost of mercenary labour $M_{i}$, immigrating from organisation $j$, which temporarily suppresses capital sponsoring $K_{i}$ in organisation $i$. However, organisation $i$ eventually prefers the support of sponsoring $K_{i}$, causing it to grow unboundedly by surviving the competition, $\lim _{t \rightarrow \infty} I_{i}$ $=\lim _{t \rightarrow \infty} K_{i}=\lim _{t \rightarrow \infty} C_{i}=\infty$, while mercenary labour $M_{i}$ is inverse $\mathrm{U}$ shaped, reaches a maximum higher than in panels a and $\mathrm{b}$, and decreases to $M_{i}=0$ when $t>13.56$. Government 
$k$ benefits from the competition, earning higher utilities than in Fig. 1 panel c2, $\lim _{t \rightarrow \infty} U_{k}$ $=\lim _{t \rightarrow \infty} U_{k a}=-\infty$.
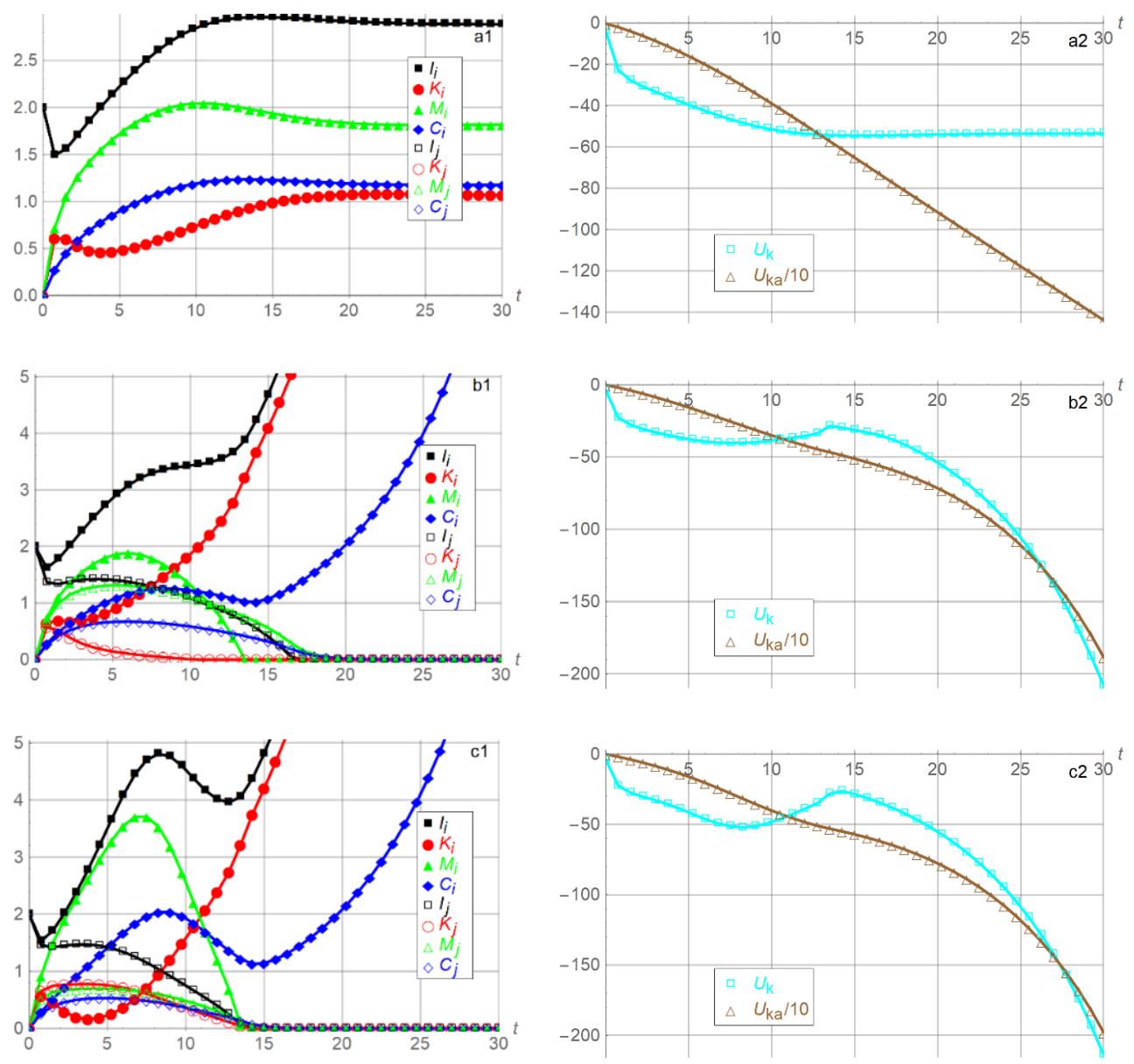

Fig. 2. Ideologue labours $I_{i}$ and $I_{j}$, capital $K_{i}$ and $K_{j}$, mercenary labours $M_{i}$ and $M j$, and captive participants labours $C_{i}$ and $C_{j}$, in $N=2$ organisations $i$ and $j, i, j=1,2, i \neq j$, and government $k$ 's instantaneous utility $U_{k}$ and accumulated utility $U_{k a}, k=1, \ldots, Q$, as functions of time $t$ with competition $\alpha_{i j}=\alpha_{j i}=0.1$ and benchmark parameter values $a_{i}=a_{j}=c_{i}=c_{j}=d_{i}=d_{j}=e_{i}=e_{j}=f_{i}=f_{j}=h_{i}=h_{j}=m_{i}=m_{j}=r_{i}=r_{j}=s_{i}=s_{j}=u_{i}=u_{j}=v_{i}=v_{j}=w_{i}=w_{j}$ $=\mu_{\text {Iijt }}=\mu_{\text {Ijit }}=\mu_{M i j t}=\mu_{M j i t}=1, b_{i}=b_{j}=g_{i}=g_{j}=0.8, \theta_{i}=\theta_{j}=0.3, \varphi_{i}=\varphi_{j}=0.6, n_{i}=n_{j}=o_{i}=o_{j}=p_{i}=p_{j}=q_{i}$ $=q_{j}=0.25, \beta_{i j}=\beta_{j i}=\gamma_{i j}=\gamma_{j i}=\lambda_{i j}=\lambda_{j i}=0, I_{i}(0)=I_{j}(0)=2, K_{i}(0)=K_{j}(0)=M_{i}(0)=M_{j}(0)$ $=C_{i}(0)=C_{j}(0)=0, A_{k i}=A_{k j}=B_{k i}=B_{k j}=D_{k i}=D_{k j}=E_{k i}=E_{k j}=\delta_{k}=1, z_{k i}=z_{k j}=0.5, G_{k l i}=G_{k l j}=G_{k K i}$ $=G_{k K j}=G_{k M i}=G_{k M j}=G_{k C i}=G_{k C j}=0$. Division of $U_{k a}$ with 10 is for scaling purposes. Panels a1 and a2: benchmark, panels b1 and b2: $\gamma_{j i t}=0.125$, panels $\mathrm{c} 1$ and $\mathrm{c} 2: \lambda_{j i t}=1$ 


\section{Analysing government intervention in two terrorist organisations with emigration and no competition as in Section 3}

Figure 3 panels a1 and a2 introduce into Fig. 1 panels a1 and a2 government intervention $G_{k I i}=G_{k I j}=0.41$ unit costs $F_{k I i}=F_{k I j}=100$ by government $k$ against ideologue labours $I_{i}$ and $I_{j}$, and $G_{k K i}=G_{k K j}=G_{k M i}=G_{k M j}=G_{k C i}=G_{k C j}=0, i, j=1,2, i \neq j$. This terminates both terrorist organisations. First, capital sponsoring decreases to $K_{i}=K_{j}=0$ when $t>16.27$. Thereafter, ideologue labours $I_{i}$ and $I_{j}$ decrease to $I_{i}=I_{j}=0$ when $t>$ 22.89, after which $G_{k l i}=G_{k l j}=0$. Mercenary labours $M_{i}$ and $M_{j}$ vanish when they have no ideologues to support, $\lim _{t \rightarrow \infty} M_{i}=\lim _{t \rightarrow \infty} M_{j}=0$, and thus also $\lim _{t \rightarrow \infty} C_{i}=\lim _{t \rightarrow \infty} C_{j}=0$. Government $k$ 's instantaneous utility $U_{k}$ approaches $\lim _{t \rightarrow \infty} U_{k}=0$, and the accumulated utility $U_{k a}$ approaches $\lim _{t \rightarrow \infty} U_{k a} / 10=-224.17$. For comparison, if government $k$ were to intervene $G_{k l i}$ $=G_{k I j}=0.4$, the organisations would not get terminated, but contained at $\lim _{t \rightarrow \infty} I_{i}=\lim _{t \rightarrow \infty} I_{j}$ $=2.77, \lim _{t \rightarrow \infty} K_{i}=\lim _{t \rightarrow \infty} K_{j}=0.75, \lim _{t \rightarrow \infty} M_{i}=\lim _{t \rightarrow \infty} M_{j}=2.02, \lim _{t \rightarrow \infty} C_{i}=\lim _{t \rightarrow \infty} C_{j}=1.20$, with $\lim _{t \rightarrow \infty} U_{k}=-130.85$ and $\lim _{t \rightarrow \infty} U_{k a}=-\infty$.

Figure 3 panels b1 and b2 introduce into Fig. 1 panels b1 and b2 (where ideologue labour $I_{i}$ in organisation $j$ moves to organisation $i$ ) government intervention $G_{k l i}=0.57$ and $G_{k l j}=0.24$ at unit $\operatorname{cost} F_{k i}=F_{k j}=100$ by government $k$ against ideologue labours $I_{i}$ and $I_{j}$, and $G_{k K i}=G_{k K j}=G_{k M i}=G_{k M j}=G_{k C i}=G_{k C j}=0, i, j=1,2, i \neq j$. This eliminates both terrorist organisations. The intervention $G_{k l i}=0.57$ is larger than $G_{k l i}=0.41$ in Fig. 3 panels a1 and a2, since organisation $i$ receives ideologue labour $I_{j}$ from organisation $j$, which causes $I_{i}$ to increase, and which is more challenging for government $k$ to terminate. Capital sponsoring decreases to $K_{i}=0$ when $t>20.02$ and to $K_{j}=0$ when $t>26.65$.

Fig. 3. Ideologue labours $I_{i}$ and $I_{j}$, capital $K_{i}$ and $K_{j}$, mercenary labours $M_{i}$ and $M_{j}$, and captive participants labours $C_{i}$ and $C_{j}$, in $N=2$ organisations $i$ and $j, i, j=1,2, i \neq j$, and government $k$ 's instantaneous utility $U_{k}$ and accumulated utility $U_{k a}, k=1, \ldots, Q$, as functions of time $t$ with competition $\alpha_{i j}=\alpha_{j i}=0.1$ and benchmark parameter values $a_{i}=a_{j}=c_{i}=c_{j}=d_{i}=d_{j}=e_{i}=e_{j}=f_{i}=f_{j}=h_{i}=h_{j}=m_{i}=m_{j}=r_{i}=r_{j}=s_{i}=s_{j}=u_{i}=u_{j}$ $=v_{i}=v_{j}=w_{i}=w_{j}=\mu_{\text {Iijt }}=\mu_{\text {lijt }}=\mu_{\text {Mijt }}=\mu_{\text {Mjit }}=1, b_{i}=b_{j}=g_{i}=g_{j}=0.8, \theta_{i}=\theta_{j}=0.3, \varphi_{i}=\varphi_{j}=0.6, n_{i}=n_{j}=o_{i}=o_{j}$ $=p_{i}=p_{j}=q_{i}=q_{j}=0.25, \alpha_{i j}=\alpha_{j i}=\beta_{i j}=\beta_{j i}=\gamma_{i j}=\gamma_{j i}=\lambda_{i j}=\lambda_{j i}=0, I_{i}(0)=I_{j}(0)=2, K_{i}(0)=K_{j}(0)=M_{i}(0)$ $=M_{j}(0)=C_{i}(0)=C_{j}(0)=0, A_{k i}=A_{k j}=B_{k i}=B_{k j}=D_{k i}=D_{k j}=E_{k i}=E_{k j}=\delta_{k}=1, z_{k i}=z_{k j}=0.5, G_{k l i}=G_{k l j}=G_{k K i}$ $=G_{k K j}=G_{k M i}=G_{k M j}=G_{k C i}=G_{k C j}=0, F_{k i}=F_{k j} 100$. Division of $U_{k a}$ with 10 is for scaling purposes. Panels a1 and a2: benchmark, panels b1 and b2: $\gamma_{j i t}=0.125, G_{k I i}=0.41, G_{k i j}=0.24$, panels c1 and c2: $\lambda_{j i t}=1, G_{k I i}=0.9$, $G_{k I j}=0.26$, panels d1 and d2: $\gamma_{j i t}=0.125, \lambda_{j i t}=1, G_{k I i}=0.9, G_{k I j}=0.26$ 

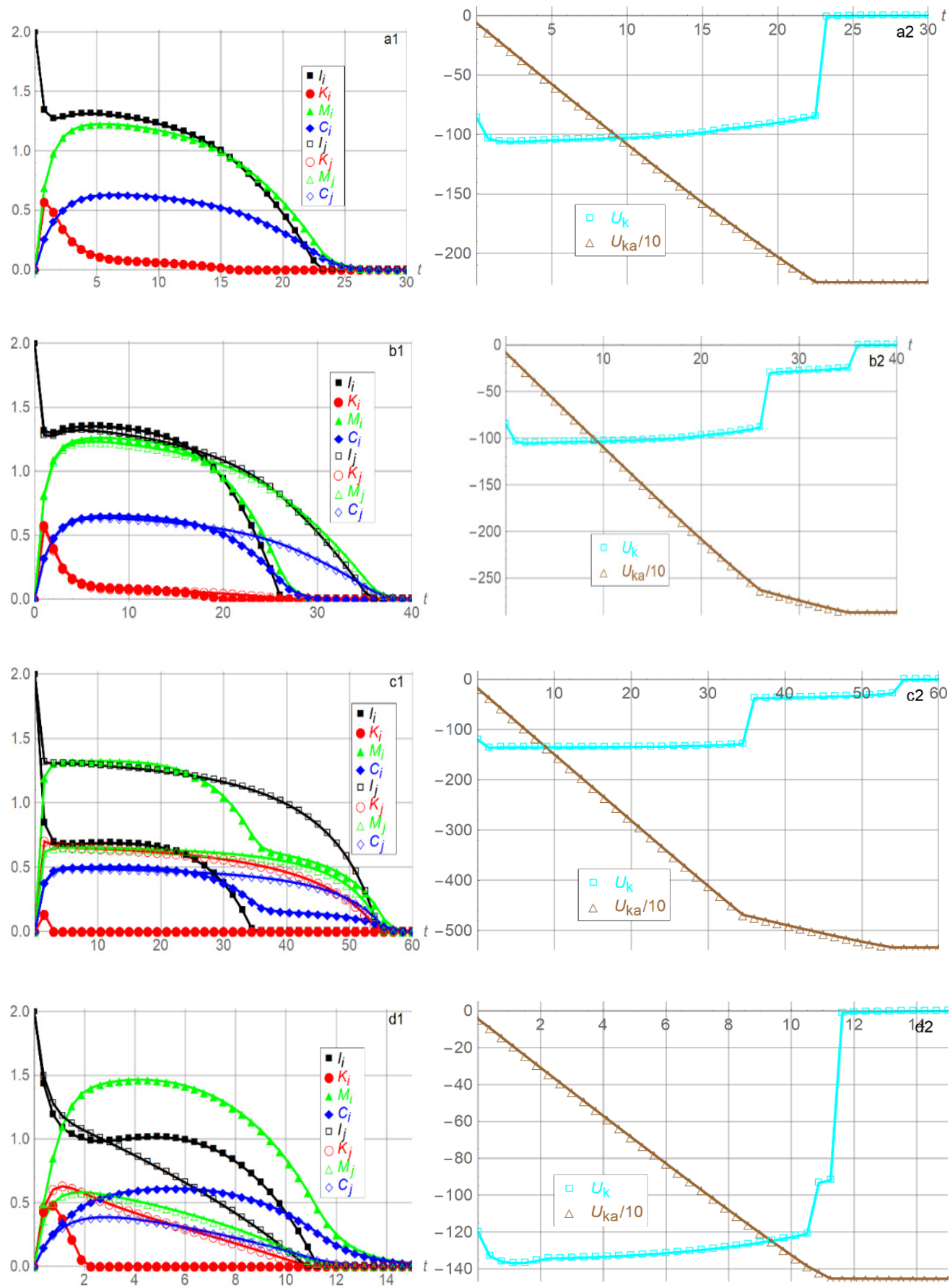
Ideologue labours decrease to $I_{i}=0$ when $t>26.13$ after which $G_{k I i}=0$, and to $I_{j}=0$ when $t>35.53$ after which $G_{k l j}=0$. Thereafter, $\lim _{t \rightarrow \infty} M_{i}=\lim _{t \rightarrow \infty} M_{j}=\lim _{t \rightarrow \infty} C_{i}=\lim _{t \rightarrow \infty} C_{j}=0$. Government $k$ 's instantaneous utility $U_{k}$ approaches $\lim _{t \rightarrow \infty} U_{k}=0$, and the accumulated utility $U_{k a}$ approaches $\lim _{t \rightarrow \infty} U_{k a} / 10=-286.83$. Intervening with $G_{k I i}=0.56$ fails to eliminate organisation $i$. Intervening with $G_{k l j}=0.23$ fails to eliminate organisation $j$.

Figure 3 panels $\mathrm{c} 1$ and $\mathrm{c} 2$ introduce into Fig. 1 panels $\mathrm{c} 1$ and $\mathrm{c} 2$ (where mercenary labour $M_{j}$ in organisation $j$ moves to organisation $i$ ) government intervention $G_{k l i}=0.9$ and $G_{k l j}=0.26$ at unit $\operatorname{cost} F_{k i}=F_{k j}=100$ by government $k$ against ideologue labours $I_{i}$ and $I_{j}$, and $G_{k K i}=G_{k K j}=G_{k M i}=G_{k M j}=G_{k C i}=G_{k C j}=0, i, j=1,2, i \neq j$. This eliminates both terrorist organisations. Capital sponsoring in organisation $i$ decreases quickly to $K_{i}=0$ when $t>1.78$ due to the drastic decrease in ideologue labour $I_{i}$, which reaches $I_{i}=0$ when $t>34.68$. Thereafter, ideologue labour $I_{j}$ in organisation $j$ decreases to $I_{j}=0$ when $t>54.68$, which decreases capital sponsoring to $K_{j}=0$ when $t>54.78$. Mercenary labours and captive participants labours in both organisations approach zero asymptotically, $\lim _{t \rightarrow \infty} M_{i}=\lim _{t \rightarrow \infty} M_{j}=\lim _{t \rightarrow \infty} C_{i}=\lim _{t \rightarrow \infty} C_{j}=0$. Government $k$ 's instantaneous utility $U_{k}$ approaches $\lim _{t \rightarrow \infty} U_{k}=0$ as the organisations approach extinction. Government $k$ 's accumulated utility $U_{k a}$ approaches $\lim _{t \rightarrow \infty} U_{k a} / 10=-533$.48. Intervening with $G_{k I i}=0.89$ fails to eliminate organisation $i$. Intervening with $G_{k i j}=0.25$ fails to eliminate organisation $j$.

Figure 3 panels $\mathrm{d} 1$ and $\mathrm{d} 2$ introduce into Fig. 1 panels $\mathrm{d} 1$ and $\mathrm{d} 2$ (where both ideologue labour $I_{j}$ and mercenary labour $M_{j}$ in organisation $j$ move to organisation $i$ ) the same government intervention as in Fig. 3 panels c1 and c2, i.e., $G_{k l i}=0.9$ and $G_{k l j}=0.26$ at unit cost $F_{k i}=F_{k j}=100$ by government $k$ against ideologue labours $I_{i}$ and $I_{j}$, and $G_{k K i}=G_{k K j}=G_{k M i}$ $=G_{k M j}=G_{k C i}=G_{k C j}=0, i, j=1,2, i \neq j$. This eliminates both terrorist organisations quicker than in panel c1. Capital sponsoring in organisation $i$ decreases to $K_{i}=0$ when $t>2.01$, contributing to ideologue labour reaching $I_{i}=0$ when $t>11.27$. Ideologue labour $I_{j}$ in organisation $j$ decreases to $I_{j}=0$ when $t>10.80$, which decreases capital sponsoring to $K_{j}=0$ when $t>10.87$. Mercenary labour $M_{i}$ in organisation $i$ experiences a high inverse $\mathrm{U}$ shape due to the inflow of mercenary labour $M_{j}$ from organisation $j$, which helps sustain ideologue labour $I_{i}$ in organisation $i$ for a while. Mercenary labours and captive participants labours in both organisations eventually approach zero asymptotically, $\lim _{t \rightarrow \infty} M_{i}=\lim _{t \rightarrow \infty} M_{j}=\lim _{t \rightarrow \infty} C_{i}=\lim _{t \rightarrow \infty} C_{j}=0$. Government $k$ 's instantaneous utility $U_{k}$ approaches $\lim _{t \rightarrow \infty} U_{k}=0$ as the organisations approach extinction. Government $k$ 's accumulated utility $U_{k a}$ approaches $\lim _{t \rightarrow \infty} U_{k a} / 10=-145.33$, which government $k$ prefers compared with panels $\mathrm{a}, \mathrm{b}$, and c. 


\section{Analysing government intervention in two terrorist organisations with emigration and competition as in Section 4}

Government intervention with the same amounts as in Fig. 3, which assumes no competition between the terrorist organisations, is advantageous for government $k$ since competition between the two terrorist organisations aids in their own destruction. This section considers alternative illuminative intervention strategies. Figure 4 panels a1 and a2 introduce into Fig. 2 panels a1 and a2 government intervention $G_{k I i}=G_{k I j}=0.27$ at unit costs $F_{k i}=F_{k j}=100$ by government $k$ against ideologue labours $I_{i}$ and $I_{j}$, and $G_{k K i}=G_{k K j}$ $=G_{k M i}=G_{k M j}=G_{k C i}=G_{k C j}=0, i, j=1,2, i \neq j$. Whereas $G_{k I i}=G_{k I j}=0.4$ fails to terminate the terrorist organisations in Fig. 3 panels a1 and a2, in Fig. 4 panels a1 and a2 both terrorist organisations are terminated, i.e., $K_{i}=K_{j}=0$ when $t>29.78, I_{i}=I_{j}=0$ when $t>38.10, \lim _{t \rightarrow \infty} M_{i}=\lim _{t \rightarrow \infty} M_{j}=\lim _{t \rightarrow \infty} C_{i}=\lim _{t \rightarrow \infty} C_{j}=0, \lim _{t \rightarrow \infty} U_{k}=0, \lim _{t \rightarrow \infty} U_{k a}=-268.93$. The termination is similar to Fig. 3 panels a1 and a2, but less intervention is needed since competition $\alpha_{i j}=\alpha_{j i}=0.1$ between the terrorist organisations aids in their demise. Lowering the intervention further to $G_{k I i}=G_{k I j}=0.26$ fails to terminate them. Instead, in Fig. 4 panels a1 and a2, a steady state situation within bounds is obtained, i.e., $\lim _{t \rightarrow \infty} I_{i}=\lim _{t \rightarrow \infty} I_{j}=2.53$, $\lim _{t \rightarrow \infty} K_{i}=\lim _{t \rightarrow \infty} K_{j}=0.45, \lim _{t \rightarrow \infty} M_{i}=\lim _{t \rightarrow \infty} M_{j}=2.08, \lim _{t \rightarrow \infty} C_{i}=\lim _{t \rightarrow \infty} C_{j}=1.15, \lim _{t \rightarrow \infty} U_{k}=-97.60$, $\lim _{t \rightarrow \infty} U_{k a}=-\infty$. Although $G_{k I i}=G_{k I j}=0.27$ is lower than $G_{k I i}=G_{k I j}=0.41$ in Fig. 3, the termination takes more time, i.e., $t>38.10$ rather than $t>22.89$ to obtain $I_{i}=I_{j}=0$. Government $k$ may not have the capacity for higher intervention than $G_{k I i}=G_{k l j}=0.27$. If government $k$ focuses on its accumulated utility $U_{k a}$, it should intervene with more than $G_{k I i}=G_{k I j}=0.27$ to ensure faster termination.

Figure 4 panels b1 and b2 introduce into Fig. 2 panels b1 and b2 (where ideologues compete and ideologue labour $I_{i}$ in organisation $j$ moves to organisation $i$ ) government intervention $G_{k I i}=0.68$ and $G_{k I j}=0$ when $0<t<13.05$ at unit costs $F_{k i}=F_{k j}=100$ by government $k$ against ideologue labour $I_{i}$ in organisation $i$, and $G_{k K i}=G_{k K j}=G_{k M i}=G_{k M j}=G_{k C i}$ $=G_{k C j}=0, i, j=1,2, i \neq j$. Whereas intervening with $G_{k I i}=0.40$ and $G_{k l j}=0.24$ fails to eliminate organisation $i$ in Fig. 3 panels b1 and b2, in Figure 4 panels b1 and b2 capital sponsoring decreases to $K_{i}=0$ when $t>10.06$, and ideologue labour decreases to $I_{i}=0$ when $t>13.04$, aided by competition $\alpha_{i j}=\alpha_{j i}=0.1$ from increasing ideologue labour $I_{j}$ in organisation $j$. Thereafter, $\lim _{t \rightarrow \infty} M_{i}=\lim _{t \rightarrow \infty} C_{i}=0$. Lower intervention $G_{k l i}=0.67$ and $G_{k l j}=0$ fails to terminate organisation $i$. Figure 4 panels b1 and b2 assume government intervention $G_{k l i}=0$ and $G_{k l j}=0.5$ when $13.05<t<28.09$. That causes capital sponsoring to decrease to $K_{j}=0$ when $t>20.13$, ideologue labour to decrease to $I_{j}=0$ when $t>28.09$, and 
$\lim _{t \rightarrow \infty} M_{j}=\lim _{t \rightarrow \infty} C_{j}=0$. Lowering the latter intervention towards organisation $j$ to $G_{k l j}=0.25$ fails to terminate it, but constrains it to $\lim _{t \rightarrow \infty} I_{j}=2.33, \lim _{t \rightarrow \infty} K_{j}=0.33, \lim _{t \rightarrow \infty} M_{j}=2.01$, $\lim _{t \rightarrow \infty} C_{j}=1.09$. Lowering the latter intervention towards organisation $j$ to $G_{k j j}=0.3$ terminates it, but is considerably more time consuming than when $G_{k l j}=0.5$. For example, capital sponsoring decreases to $K_{j}=0$ when $t>75.54$. Government $k$ 's instantaneous utility $U_{k}$ approaches $\lim _{t \rightarrow \infty} U_{k}=0$. Government $k$ 's accumulated utility $U_{k a}$ approaches $\lim _{t \rightarrow \infty} U_{k a} / 10$ $=-212.46$. Also here, if government $k$ focuses on its accumulated utility $U_{k a}$, and has sufficient budget, it should to some extent intervene more to ensure faster termination.

Figure 4 panels $\mathrm{c} 1$ and $\mathrm{c} 2$ introduce into Fig. 2 panels $\mathrm{c} 1$ and $\mathrm{c} 2$ (where ideologues compete and mercenary labour $M_{j}$ in organisation $j$ moves to organisation $i$ ) government intervention $G_{k l i}=0.69$ and $G_{k l j}=0$ when $0<t<30.62$ at unit costs $F_{k i}=F_{k j}=100$ by government $k$ against ideologue labour $I_{i}$ in organisation $i$, and $G_{k K i}=G_{k K j}=G_{k M i}=G_{k M j}$ $=G_{k C i}=G_{k C j}=0, i, j=1,2, i \neq j$. Intervening with $G_{k l i}=0.68$ and $G_{k l j}=0$, as in Fig. 4 panels $\mathrm{b} 1$ and $\mathrm{b} 2$, is insufficient to eliminate organisation $i$. Whereas intervening with $G_{k I i}=0.89$ and $G_{k I j}=0.26$ fails to eliminate organisation $i$ in Fig. 4 panels b1 and b2, in Fig. 4 panels $\mathrm{c} 1$ and $\mathrm{c} 2$ capital sponsoring of organisation $i$ decreases quickly to $K_{i}=0$ when $t>1.83$, mainly caused by the substantial immigration of mercenary labour $M_{j}$ from organisation $j$. Supported by mercenary labour $M_{i}$, and immigration of ideologue labour $I_{j}$ from organisation $j$, ideologue labour $I_{i}$ in organisation $i$ continues to grow despite the substantial government intervention $G_{k l i}=0.69$. However, ideologue labour $I_{j}$ in organisation $j$ grows more due to no government intervention $G_{k l j}=0$. Mercenary labour $M_{j}$ in organisation $j$ experiences an inverse $\mathrm{U}$ shape, due to emigration to organisation $i$, and reaches $M_{j}=0$ when $t>22.86$. That causes mercenary labour $M_{i}$ in organisation $i$ to decrease substantially, $\lim _{t \rightarrow \infty} M_{i}=\lim _{t \rightarrow \infty} C_{i}=0$. With support of neither capital sponsoring $K_{i}$ nor mercenary labour $M_{i}$, substantial government intervention $G_{k l i}=0.69$, and ideologue competition $\alpha_{i j}=\alpha_{j i}=0.1$ with organisation $j$, ideologue labour in organisation $i$ decreases to $I_{i}=0$ when $t>30.62$. Figure 4 panels $\mathrm{c} 1$ and $\mathrm{c} 2$ assume government intervention $G_{k l i}=0$ and $G_{k l j}=3$ when $30.62<t<38.64$, and $\lim _{t \rightarrow \infty} M_{i}=\lim _{t \rightarrow \infty} C_{i}=0$, which terminates organisation $j$. Government intervention $G_{k l i}=0$ and $G_{k I j}=2.5$ causes $I_{j}=0$ when $t>42.78$. Lower government intervention $G_{k l j}=2$ causes unbounded growth of organisation $j$. Government $k$ 's instantaneous utility $U_{k}$ approaches $\lim _{t \rightarrow \infty} U_{k}=0$. Government $k$ 's accumulated utility $U_{k a}$ approaches $\lim _{t \rightarrow \infty} U_{k a} / 10=-446.12$. If government $k$ focuses on its accumulated utility $U_{k a}$, and has sufficient budget, it should to some extent 
intervene more, and earlier, to ensure faster termination. In particular, eliminating organisation $i$ earlier, and then intervening to eliminate organisation $j$, prevents organisation $j$ to grow substantially before elimination.
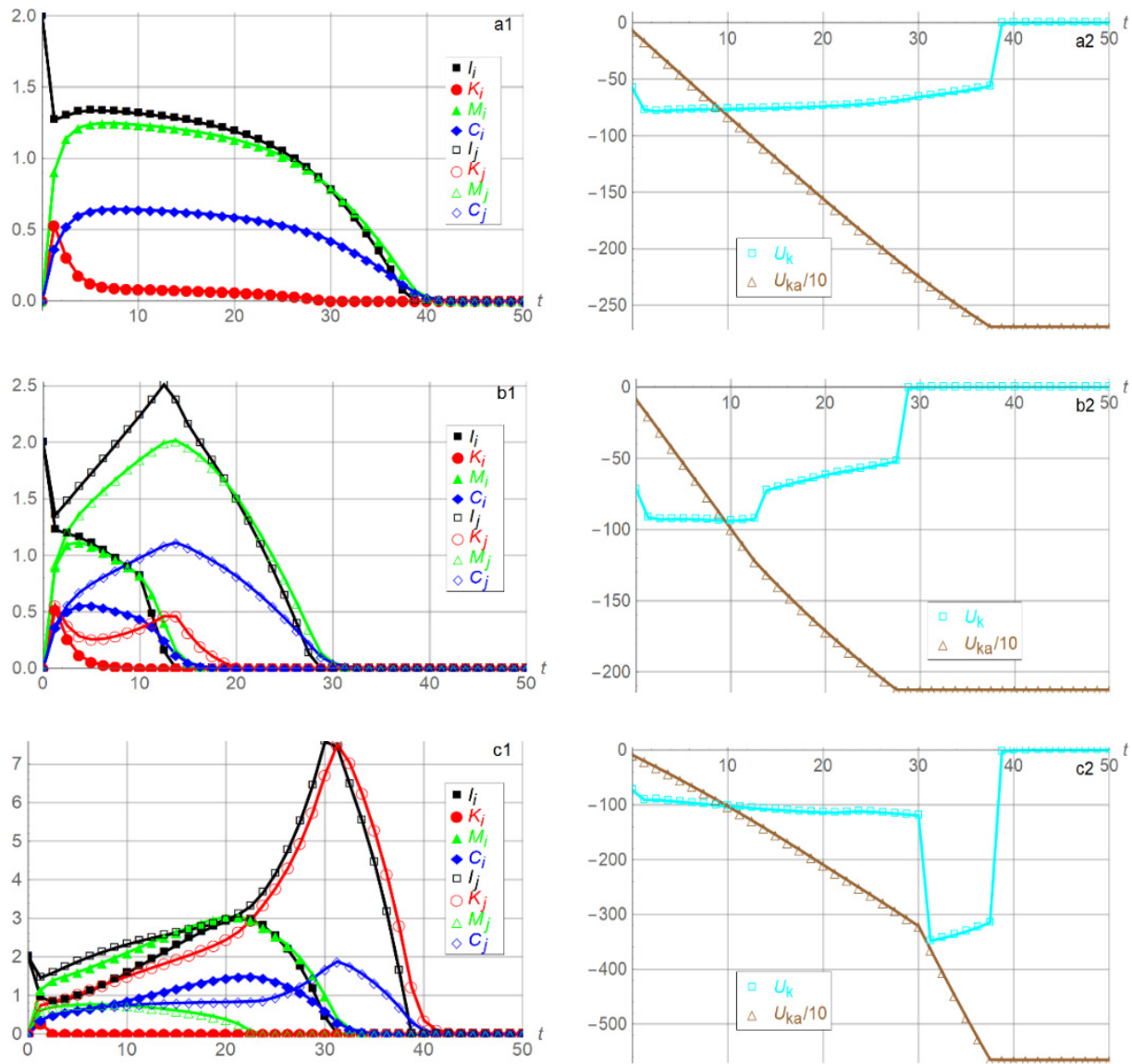

Fig. 4. Ideologue labours $I_{i}$ and $I_{j}$, capital $K_{i}$ and $K_{j}$, mercenary labours $M_{i}$ and $M j$, and captive participants labours $C_{i}$ and $C_{j}$, in $N=2$ organisations $i$ and $j, i, j=1,2, i \neq j$, and government $k$ 's instantaneous utility $U_{k}$ and accumulated utility $U_{k a}, k=1, \ldots, Q$, as functions of time $t$ with competition $\alpha_{i j}=\alpha_{j i}=0.1$ and benchmark parameter values $a_{i}=a_{j}=c_{i}=c_{j}=d_{i}=d_{j}=e_{i}=e_{j}=f_{i}=f_{j}=h_{i}=h_{j}=m_{i}=m_{j}=r_{i}=r_{j}=s_{i}=s_{j}=u_{i}=u_{j}=v_{i}=v_{j}=w_{i}$ $=w_{j}=\mu_{\text {Iijt }}=\mu_{\text {Ijit }}=\mu_{\text {Mijt }}=\mu_{\text {Mjit }}=1, b_{i}=b_{j}=g_{i}=g_{j}=0.8, \theta_{i}=\theta_{j}=0.3, \varphi_{i}=\varphi_{j}=0.6, n_{i}=n_{j}=o_{i}=o_{j}=p_{i}=p_{j}$ $=q_{i}=q_{j}=0.25, \beta_{i j}=\beta_{j i}=\gamma_{i j}=\gamma_{j i}=\lambda_{i j}=\lambda_{j i}=0, I_{i}(0)=I_{j}(0)=2, K_{i}(0)=K_{j}(0)=M_{i}(0)=M_{j}(0)=C_{i}(0)=C_{j}(0)=0$, $A_{k i}=A_{k j}=B_{k i}=B_{k j}=D_{k i}=D_{k j}=E_{k i}=E_{k j}=\delta_{k}=1, z_{k i}=z_{k j}=0.5, G_{k l i}=G_{k l j}=G_{k K i}=G_{k K j}=G_{k M i}=G_{k M j}=G_{k C i}$ $=G_{k C j}=0, F_{k i}=F_{k j}=100$. Division of $U_{k a}$ with 10 is for scaling purposes. Panels a1 and a2: benchmark, $G_{k l i}$ $=G_{k l j}=0.27$, panels b1 and b2: $\gamma_{j i t}=0.125, G_{k l i}=0.68$ and $G_{k l j}=0$ when $0<t<13.05$, and $G_{k l i}=0$ and $G_{k l j}=0.5$ when $13.05<t<28.09$, panels $\mathrm{c} 1$ and $\mathrm{c} 2: \lambda_{j i t}=1, G_{k l i}=0.69$ and $G_{k l j}=0$ when $0<t<30.62$, and $G_{k l i}=0$ and $G_{k l j}=3$ when $30.62<t<38.64$ 


\section{Conclusion}

A model is developed to analyse migration and competition through time between terrorist organisations subject to government intervention. Each terrorist organisation is composed of ideologues, criminal mercenaries, and captive participants, and may be supported by sponsors. The evolution of the three labours and capital sponsoring is analysed with four coupled differential time equations. Ideologues and mercenaries may migrate between the terrorist organisations, which may compete with each other. Governments may intervene to regulate, control, prevent unbounded growth, or eradicate the terrorist organisations.

For two terrorist organisations, we first analyse a typical and illustrative benchmark of neither emigration, competition, nor government intervention. Ideologue labour grows supported by growing capital sponsoring and captive participants labour, while mercenary labour vanishes. Emigration of ideologues causes unbounded growth for the organisation receiving ideologues, while the organisation losing ideologues reaches a stationary state where ideologues are supported by both capital sponsoring and mercenaries which tolerate each other. Emigration of mercenaries causes the organisation losing mercenaries to experience growth. The organisation receiving mercenaries experiences a dip in capital sponsoring. If the dip is temporary and capital sponsoring rebounds, mercenaries vanish and the organisation grows. Emigration of both ideologues and mercenaries may eradicate an organisation.

Introducing competition between terrorist organisations may prevent their unbounded growth. Competition and emigration of ideologues or mercenaries may eliminate an organisation that would survive without competition.

Government intervention is shown to contain or eliminate terrorist organisations that would otherwise grow. Emigration of ideologues or mercenaries from one organisation to another requires more government intervention into the latter than the former to eliminate both organisations. Emigration of both ideologues and mercenaries from one organisation to another may enable quicker elimination since mercenaries more quickly go extinct in the former organisation. No immigration of mercenaries into the latter means less support for the ideologues which are then more easily terminated by government intervention.

Government intervention more easily extinguishes competing terrorist organisations since competition facilitates their extinction. Various alternative intervention strategies are considered where the most threatening organisation is eliminated first, aided by the competition from the least threatening organisation, after which the remaining organisation is eliminated. The government's instantaneous and accumulated utilities are analysed through time and compared depending on emigration, competition, and government intervention strategies. 
The article provides tools to analyse government intervention through time into terrorist organisations interacting through migration and competition while accounting for how each terrorist organisation functions and evolves internally. Future research should gather empirical data to compare against the model and gain a richer understanding of how to fight terrorism. Future research may also analyse the phenomenon by applying other tools, e.g., a differential game approach.

\section{Nomenclature}

$Q \quad$ - number of governments, $Q \geq 1$

$N \quad-$ number of terrorist organisations, $N \geq 1$

$t \quad-$ time, $t \geq 0$

$I_{i} \quad-$ amount or stock of labour exerted by ideologues in terrorist organisation, $i=1, \ldots, N, I_{i} \geq 0$

$K_{i} \quad-$ amount of capital provided by sponsors to terrorist organisation, $i=1, \ldots, N, K_{i} \geq 0$

$M_{i} \quad-$ amount or stock of labour exerted by mercenaries in terrorist organisation $i=1, \ldots, N, M_{i} \geq 0$

$C_{i} \quad-$ amount or stock of labour exerted by captive participants in terrorist organisation $i, \ldots, N, C_{i} \geq 0$

$G_{k l i} \quad-$ government $k$ 's labour effort at time $t$ to combat ideologue labour $I_{i}, k=1, \ldots, Q,-\infty<G_{k I i}<\infty$

$G_{k K i} \quad-$ government $k$ 's labour effort at time $t$ to combat capital $K_{i}, k=1, \ldots, Q,-\infty<G_{k K i}<\infty$

$G_{k M i} \quad-$ government $k$ 's labour effort at time $t$ to combat mercenary labour $M_{i}, k=1, \ldots, Q,-\infty<G_{k M i}<\infty$

$G_{k C i} \quad-$ government $k$ 's labour effort at time $t$ to combat captive participants $C_{i}, k=1, \ldots, Q,-\infty<G_{k C i}<\infty$

$\alpha_{i j} \quad-$ loss rate for organisation $i$ due to ideologue competition or warfare with organisation $j, i, j=1, \ldots, N$, $i \neq j, \alpha_{i j} \geq 0$

$\beta_{i j} \quad-$ loss rate for organisation $i$ due to mercenary competition or warfare with organisation $j, i, j=1, \ldots, N$, $i \neq j, \beta_{i j} \geq 0$

$x_{i j} \quad-$ fraction of ideologue labour $I_{i}$ fighting organisation $j, 0 \leq x_{i j} \leq 1, \sum_{j=1, j \neq i}^{N} x_{i j}=1$

$y_{i j} \quad-$ fraction of mercenary labour $M_{i}$ fighting organisation $j, 0 \leq y_{i j} \leq 1, \sum_{j=1, j \neq i}^{N} y_{i j}=1$

$\gamma_{i j t}=-\gamma_{j i t}-$ attractiveness of organisation $j$ relative to organisation $i$ for ideologue labour $I_{i}$ at time $t$, $-\infty<\gamma_{i j t}<\infty$

$\lambda_{i j t}=-\lambda_{j i t}-$ attractiveness of organisation $j$ relative to organisation $i$ for mercenary labour $M_{i}$ at time $t$, $-\infty<\lambda_{i j t}<\infty$

$\mu_{\text {Iijt }} \quad$ - terrorist organisation $i$ 's control parameter for the outflow of ideologue labour $I_{i}$ from organisation $i$ to organisation $j$ at time $t, 0 \leq \mu_{I j t} \leq 1$

$\mu_{M i j t} \quad-$ terrorist organisation $i$ 's control parameter for the outflow of mercenary labour $M_{i}$ from organisation $i$ to organisation $j$ at time $t, 0 \leq \mu_{M i j t} \leq 1$

$a_{i} \quad-$ growth rate for capital $K_{i}$ impacting ideologue labour $I_{i}, a_{i} \geq 0$

$c_{i} \quad-$ growth rate for ideologue labour $I_{i}$ impacting capital sponsoring $K_{i}, c_{i} \geq 0$

$b_{i} \quad-$ depreciation rate of ideologue labour $I_{i} b_{i} \geq 0$

$d_{i} \quad-$ depreciation rate of capital $K_{i}, d_{i} \geq 0$

$e_{i} \quad-$ growth rate for mercenary labour $M_{i}$ impacting ideologue labour $I_{i}, e_{i} \geq 0$

$f_{i} \quad-$ depreciation rate of mercenary labour impacting $M_{i}$ capital sponsoring $K_{i}, f_{i} \geq 0$ 
$g_{i} \quad-$ growth rate for ideologue labour $I_{i}$ impacting mercenary labour $M_{i}, g_{i} \geq 0$

$h_{i} \quad-$ growth rate for capital $K_{i}$ impacting mercenary labour $M_{i}, h_{i} \geq 0$

$m_{i} \quad-$ depreciation rate of mercenary labour $M_{i}, m_{i} \geq 0$

$\theta_{i} \quad-$ depreciation rate of the product $K_{i} M_{i}$ of capital $K_{i}$ and mercenary labour $M_{i}, \theta_{i} \geq 0$

$\varphi_{i} \quad-$ depreciation rate of the product $I_{i} K_{i}$ of ideologue labour $I_{i}$ and capital $K_{i}, \varphi_{i} \geq 0$

$n_{i} \quad-$ growth rate for captive participants $C_{i}$ impacting ideologue labour $I_{i}, n_{i} \geq 0$

$o_{i} \quad-$ growth rate for captive participants $C_{i}$ impacting mercenary labour $M_{i}, o_{i} \geq 0$

$p_{i} \quad-$ growth rate for ideologue labour $I_{i}$ impacting captive participants $C_{i}, p_{i} \geq 0$

$q_{i} \quad$ - growth rate for mercenary labour $M_{i}$ impacting captive participants $C_{i}, q_{i} \geq 0$

$r_{i} \quad-$ depreciation rate of captive participants $C_{i}, r_{i} \geq 0$

$s_{i} \quad-$ unit effort costs of government labour to combat ideologue labour $I_{i}, s_{i} \geq 0$

$u_{i} \quad-$ unit effort costs of government labour to combat capital $K_{i}, u_{i} \geq 0$

$v_{i} \quad-$ unit effort costs of government labour to combat mercenary labour $M_{i}, v_{i} \geq 0$

$w_{i} \quad-$ unit effort costs of government labour to combat captive participants $C_{i}, w_{i} \geq 0$

$U_{k i} \quad-$ government $k$ 's instantaneous utility at time $\tau, 0 \leq \tau \leq t$, due to the presence of terrorist organisation $i=1, \ldots, N,-\infty<U_{k i}<\infty$

$U_{k a i} \quad-$ government $k$ 's accumulated utility due to terrorist organisation $i=1, \ldots, N$ from time $\tau=0$ to time $\tau=t, U_{k a i}=\int_{\tau=0}^{\tau=t} \delta_{k}^{\tau} U_{k i} d \tau,-\infty<U_{k a i}<\infty$

$A_{k i} \quad-$ weight parameter for $I_{i}$ for government $k$ for the constant elasticity of substitution utility, $A_{k i} \geq 0$

$B_{k i} \quad-$ weight parameter for $K_{i}$ for government $k$ for the constant elasticity of substitution utility, $B_{k i} \geq 0$

$D_{k i} \quad-$ weight parameter for $M_{i}$ for government $k$ for the constant elasticity of substitution utility, $D_{k i} \geq 0$

$E_{k i} \quad-$ weight parameter for $C_{i}$ for government $k$ for the constant elasticity of substitution utility, $E_{k i} \geq 0$

$1 /\left(1-z_{k i}\right)-$ government $k$ 's elasticity of substitution as impacted by terrorist organisation $i=1, \ldots, N$, $-\infty<z_{k i} \leq 1$

$F_{k i} \quad-$ government $k$ 's unit cost of exerting effort $G_{k l i}$ at time $t$ to combat ideologue labour $I_{i}, F_{k i} \geq 0$

$H_{k i} \quad-$ government $k$ 's unit cost of exerting effort $G_{k K i}$ at time $t$ to combat capital $K_{i}, H_{i} \geq 0$

$J_{k i} \quad-$ government $k$ 's unit cost of exerting effort $G_{k M i}$ at time $t$ to combat mercenary labour $M_{i}, J_{i} \geq 0$

$L_{k i} \quad-$ government $k$ 's unit cost of exerting effort $G_{k C i}$ at time $t$ to combat captive participants $C_{i}, L_{i} \geq 0$

$\delta_{k} \quad-$ government $k$ 's time discount parameter, $0 \leq \delta_{k} \leq 1$

\section{Acknowledgement}

Three anonymous referees of this journal are thanked for their useful comments.

\section{References}

[1] Abbas A.E., Tambe M., Von Winterfeldt D., Improving Homeland Security Decisions, Cambridge University Press, Cambridge 2017.

[2] Berman O., Gavious A., Location of Terror Response Facilities. A Game Between State and Terrorist, Eur. J. Oper. Res., 2007, 177 (2), 1113-1133.

[3] BiER V.M., HAusKen K., Endogenizing the Sticks and Carrots. Modeling Possible Perverse Effects of Counterterrorism Measures, Ann. Oper. Res., 2011, 186 (1), 39-59. 
[4] Bunn M., A Mathematical Model of the Risk of Nuclear Terrorism, Ann. Am. Acad. Pol. Soc. Sci., 2006, 607 (1), 103-120.

[5] Caulkins J.P., Grass D., Feichtinger G., Tragler G., Optimizing Counter-Terror Operations. Should one Fight Fire With "Fire” or “Water"?, Comp. Oper. Res., 2008, 35 (6), 1874-1885.

[6] Chamberlain T., Systems Dynamics Model of Al-Qa'ida and United States, J. Home. Sec. Emerg. Manage., 2007, 4 (3), article No. 14, http://www.bepress.com/jhsem /vol4/iss3/14/

[7] Feichtinger G., Novak A., Terror and Counterterror Operations. Differential Game with Cyclical Nash Solution, J. Opt. Theor. Appl., 2008, 139 (3), 541-556.

[8] FeinsteIn J., Kaplan E., Analysis of a Strategic Terror Organization, J. Conf. Res., 2010, 54 (2), 281-302.

[9] Golany B., Kaplan E.H., Marmur A., Rothblum U.G., Nature Plays with Dice. Terrorists Do Not: Allocating Resources to Counter Strategic Versus Probabilistic Risks, Eur. J. Oper. Res., 2009, 192 (1), 198-208.

[10] Guan P., He M., Zhuang J., Hora S.C., Modeling a Multitarget Attacker-Defender Game with Budget Constraints, Dec. Anal., 2017, 14 (2), 87-107.

[11] GuPTA D.K., Understanding Terrorism. The Life Cycle of Birth, Growth, Transformation, and Demise. Routledge, New York 2008.

[12] Hausken K., The Dynamics of Terrorist Organizations, Oper. Res. Persp., 2019, 6, https://doi.org/ 10.1016/j.orp.2019.100120

[13] HaUSKEn K., Government Intervention to Combat the Dynamics of Terrorist Organizations, J. Oper. Res. Soc., 2020, https://doi.org/10.1080/01605682.2019.1656561

[14] HaUSKEn K., Government Protection Against Terrorists Funded by Benefactors and Crime: an Economic Model, Int. J. Conf. Viol., 2017, 11 (5), 1-37.

[15] HaUSKEn K., Governmental Combat of the Dynamics of Multiple Competing Terrorist Organizations, Math. Comp. Simul., 2019, 166, 33-55.

[16] HaUSKEn K., Governments Playing Games and Combating the Dynamics of a Terrorist Organization, Int. Game Theory Rev., 2020, https://doi.org/10.1142/S0219198920500139

[17] HAUSKEN K., Whether to Attack a Terrorist's Resource Stock Today or Tomorrow, Games Econ. Beh., 2008, 64 (2), 548-564.

[18] Hausken K., Banuri S., Gupta D.K., AbBink K., Al Qaeda at the Bar. Coordinating Ideologues and Mercenaries in Terrorist Organizations, Publ. Choice, 2015, 164 (1), 57-73.

[19] Hausken K., BIER V.M., Defending against Multiple Different Attackers, Eur. J. Oper. Res., 2011, 211 (2), 370-384.

[20] Hausken K., GuPTA D.K., Determining the Ideological Orientation of Terrorist Organizations: the Effects of Government Repression and Organized Crime, Int. J. Publ. Pol., 2016, 12 (1-2), 71-97.

[21] HAUSKEN K., GuPTA D.K., Government Protection Against Terrorism and Crime, Global Crime, 2015, 16 (2), 59-80.

[22] HausKen K., GuPTA D.K., Terrorism and Organized Crime: the Logic of an Unholy Alliance, Int. J. Cont. Soc., 2015, 52 (2), 141-166.

[23] Hausken K., Moxnes J.F., Stochastic Conditional and Unconditional Warfare, Eur. J. Oper. Res., 2002, $140(1), 61-87$.

[24] Hausken K., Zhuang J., Governments' and Terrorists' Defense and Attack in a T-Period Game, Dec. Anal., 2011, 8 (1), 46-70.

[25] HirshleIFER J., Anarchy and Its Breakdown, J. Pol. Econ., 1995, 103 (1), $26-52$.

[26] Insua D.R., Cano J., Pellot M., Ortega R., Multithreat Multisite Protection. A Security Case Study, Eur. J. Oper. Res., 2016, 252 (3), 888-899.

[27] KAMINSKIY M.P., AYYUB B.M., Terrorist Population Dynamics Model, Risk Anal., 2006, 26 (3), 747-752.

[28] Salop S.C., Scheffman D.T., Raising Rivals' Costs, Am. Econ. Rev., 1983, 73 (2), 267-271. 
[29] SAPERSTEIN A.M., Mathematical Modeling of the Interaction Between Terrorism and Counter-Terrorism and Its Policy Implications, Complexity, 2008, 14 (1), 45-49.

[30] Shan X., Zhuang J., Modeling Cumulative Defensive Resource Allocation Against a Strategic Attacker in a Multi-Period Multi-Target Sequential Game, Rel. Eng. Syst. Saf., 2018, 179, 12-26.

[31] Tullock G., The Welfare Costs of Tariffs, Monopolies, and Theft, West. Econ. J., 1967, 5, 224-232 [Online], available: $\mathrm{http}: / /$ search.ebscohost.com/login.aspx?direct=true \&db=eoh\&AN=1222544\&scope=site

[32] Udwadia F., Leitmann G., Lambertini L., A Dynamical Model of Terrorism, Disc. Dynam. Nature Soc., 2006, DOI: 10.1155/DDNS/2006/85653.

[33] Xu Z., Zhuang J., A Study on a Sequential One-Defender-N-Attacker Game, Risk Anal., 2019, 39 (6), $1414-1432$.

[34] Zhang J., Zhuang J., Modeling a Multi-Target Attacker-Defender Game with Multiple Attack Types, Rel. Eng. Syst. Saf., 2019, 185, 465-475.

[35] Zhang J., Zhuang J., Jose V.R.R., The Role of Risk Preferences in a Multi-Target Defender-Attacker Resource Allocation Game, Rel. Eng. Syst. Saf., 2018, 169, 95-104. 